\title{
Tubular epithelial cells in renal clear cell carcinoma express high RIPK1/3 and show increased susceptibility to TNF receptor 1-induced necroptosis
}

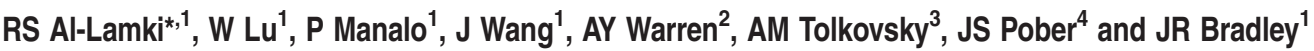

\begin{abstract}
We previously reported that renal clear cell carcinoma cells (RCC) express both tumor necrosis factor receptor (TNFR)-1 and -2, but that, in organ culture, a TNF mutein that only engages TNFR1, but not TNFR2, causes extensive cell death. Some RCC died by apoptosis based on detection of cleaved caspase 3 in a minority TUNEL-positive cells but the mechanism of death in the remaining cells was unexplained. Here, we underpin the mechanism of TNFR1-induced cell death in the majority of TUNEL-positive RCC cells, and show that they die by necroptosis. Malignant cells in high-grade tumors displayed threefold to four fold higher expression of both receptor-interacting protein kinase (RIPK)1 and RIPK3 compared with non-tumor kidney tubular epithelium and low-grade tumors, but expression of both enzymes was induced in lower grade tumors in organ culture in response to TNFR1 stimulation. Furthermore, TNFR1 activation induced significant MLKL ${ }^{\text {Ser358 }}$ and Drp1 ${ }^{\text {Ser616 }}$ phosphorylation, physical interactions in RCC

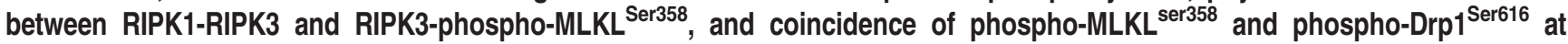
mitochondria in TUNEL-positive RCC. A caspase inhibitor only partially reduced the extent of cell death following TNFR1 engagement in RCC cells, whereas three inhibitors, each targeting a different step in the necroptotic pathway, were much more protective. Combined inhibition of caspases and necroptosis provided additive protection, implying that different subsets of cells respond differently to TNF- $\alpha$, the majority dying by necroptosis. We conclude that most high-grade RCC cells express increased amounts of RIPK1 and RIPK3 and are poised to undergo necroptosis in response to TNFR1 signaling.
\end{abstract}

Cell Death and Disease (2016) 7, e2287; doi:10.1038/cddis.2016.184; published online 30 June 2016

Renal clear cell carcinoma (RCC) is resistant to chemotherapy and 5-year survival rates of metastatic disease are only $5-15 \%{ }^{1}$ Many anticancer agents act via induction of apoptosis, and apoptotic deficiency may be a cause of chemoresistance. However, recent studies have identified a caspase-independent form of programmed cell death, termed necroptosis, ${ }^{2}$ that may provide an alternative pathway for tumor killing. ${ }^{3,4}$ Tumor necrosis factor- $a$ (TNF), acting through TNF receptor 1 (TNFR1), induces apoptosis of many different types of malignant cells through caspase 8 activation, which is mediated through the assembly of a signaling complex involving TNFR-associated protein with a death domain (TRADD), receptor-interacting protein kinase 1 (RIPK1), TNFR-associated factor 2 (TRAF2) and Fasassociated protein with a death domain (FADD). ${ }^{5}$ Alternatively, TNF can induce necroptosis, also via TNFR1, through a pathway involving TRADD, RIPK1 and RIPK3. ${ }^{2,6-10}$ Signaling through TNFR2, which is also expressed on RCC cells, does not generally induce cell death, but can potentiate TNFR1mediated programmed necrosis via TNFR1 ${ }^{11}$ Activation of caspase 8 generally inhibits death by necroptosis so that necroptosis is more evident when caspase activation is inhibited or in cells lacking FADD or caspase $8^{12,13}$ In necroptosis, RIPK1 is recruited to TRADD via a death domain (DD) located in its $\mathrm{C}$ terminus ${ }^{14,15}$ and RIPK1 then recruits RIPK3, forming a necroptosis-inducing 'ripoptosome complex $^{16}$ that phosphorylates pseudokinase mixed lineage kinase domain-like (MLKL) at residues threonine 357 and serine 358 in humans ${ }^{15,17-19}$ and serine 345 in mice. ${ }^{20}$ The events that follow may be cell type-specific, but in some cells, this promotes MLKL association with the mitochondrial phosphatase PGAM5 and dyamin-related protein 1 (Drp1), a cytosolic dynamin GTPase. Dephosphorylation of Drp1 at serine 637 by PGAM5 results in Drp1 activation, ${ }^{15,21,22}$ which leads to mitochondrial fragmentation and necroptosis. ${ }^{23}$ Loss of Drp1 function has been shown to slow down necrosis in

\footnotetext{
${ }^{1}$ Department of Medicine, University of Cambridge, Addenbrooke's Hospital, Cambridge CB2 OQQ, UK; ${ }^{2}$ Department of Pathology, University of Cambridge, Addenbrooke's Hospital, Cambridge CB2 0QQ, UK; ${ }^{3}$ Department of Clinical Neurosciences, University of Cambridge, Addenbrooke's Hospital, Cambridge CB2 0QQ, UK and ${ }^{4}$ Department of Immunobiology, Yale University School of Medicine, New Haven, CT 06510, USA

*Corresponding author: RS Al-Lamki, Department of Medicine, University of Cambridge, Addenbrooke's Hospital, Cambridge University NHS Trust Hospitals, P.O. Box 157, Level 5 Hill's Road, Cambridge CB2 0QQ, UK. Tel: +44 1223 336745, Fax: +44 1223 336846; E-mail: rsma2@ @ermes.cam.ac.uk

Abbreviations: RCC, renal clear cell carcinoma; NK, normal human kidney; TNF, tumor necrosis factor; TNFR1, tumor necrosis factor receptor 1; TNFR2, tumor necrosis factor receptor 2; UT, untreated; wtTNF, wild-type tumor necrosis factor; R1TNF, TNFR1-selective mutein; R2TNF, TNFR2-selective mutein; RIPK1, receptor-interacting protein kinase 1; RIPK3, receptor-interacting protein kinase 3; MLKL, mixed lineage kinase domain; pMLKL Ser358, Mixed lineage kinase domain phosphorylated at Serine 358; Drp1, Dyamin-related protein 1; pDrp1 ${ }^{\text {err637 }}$, Dyamin-related protein 1 phosphorylated at Serine 637; pDrp1 ${ }^{\text {Ser616 }}$, Dyamin-related protein 1 phosphorylated at Serine 616; FADD, fas-associated protein with a death domain; TRADD, TNFR-associated protein with a death domain; c-Flip, cellular FLICE-inhibitory protein; mTECs, malignant tubular epithelial cells; MNCs, infiltrating mononuclear cells; VECs, vascular endothelial cells; Nec-1, necrostatin-1; NSA, necrosulfonamide; zVAD.fmk, carbobenzoxy-valyl-alanyl-aspartyl-[O-methyl]- fluoromethylketone; PDTC, pyrrolidine diothiocarbamate; NF $\kappa$, nuclear factor $\kappa \mathrm{B}$; PGAM5, phosphoglycerate mutase 5 ; PLA, proximity ligation assay; TUNEL, Terminal deoxynucleotidyl transferase dUTP nick end labeling

Received 24.9.15; revised 26.5.16; accepted 31.5.16; Edited by P Ekert
} 
Caenorhabditis elegans ${ }^{24}$ and inhibition of its activity delays cell death. ${ }^{25}$ Phosphorylation of serine 616 promotes Drp1 activity and tumor growth. ${ }^{26}$ This new understanding of the signal transduction pathway leading to necroptosis offers the opportunity to target this process therapeutically. We have used organ culture to study the responses of RCC cells to TNF signaling. ${ }^{5}$ The advantage of using organ culture is that it preserves the relationship between the various cell types within the cancer milieu and also preserves adjacent normal tissue, which can be used as an endogenous control. We previously reported that ligation of TNFR1 promotes cell death in malignant tubular epithelial cells (mTECs) in RCC, which we had attributed to apoptosis based on detection of cleaved caspase 3 in some of the TUNEL-positive cells. ${ }^{27}$ These initial studies antedated the elucidation of the necroptotic process. In the present study, we show that both apoptosis and necroptosis occur within the same tumor and that necroptosis may be the dominant pathway of cell death in TNF-treated RCC.

\section{Results}

RIPK1 and RIPK3 are highly expressed in RCC and are upregulated by TNF. In an earlier report, ${ }^{27}$ we showed that $\sim 10 \%$ of RCC cells in organ culture die by apoptosis in response to TNF, via the TNFR1 receptor. However, we noted that more cells died than those accounted for by apoptosis alone. One possible explanation is that some of the cells were dying by necroptosis. To study whether RCC cells die by necroptosis, we analyzed RCC cells more thoroughly for signs of necrosis. There was about $70-80 \%$ cell death in RCC organ cultures treated with wtTNF or R1TNF compared with the control group (UT) or R2TNF-treated cultures (Figure 1A). A closer examination by electron microscopy identified features of necrosis in mTECs such as numerous large and small cytoplasmic vacuoles, condensation of the chromatin into small, irregular, circumscribed patches, increased translucent cytoplasm, swelling of organelles and disruption of the plasma membrane ${ }^{28}$ (Figure 1B). Many of the necrotic cells contained $\mathrm{TUNEL}^{+}$nuclei, indicating DNA fragmentation, a feature widely associated with apoptosis but also well documented to occur in primary necrosis. ${ }^{29,30}$ Although TECs were the majority of cells displaying necrosis, some vascular endothelial cells and infiltrating mononuclear cells (MNCs) were also TUNEL ${ }^{+}$(Supplementary Figure 1A, quantified in Supplementary Figure 1B).

TNF is known to induce necroptosis via RIPK1/3. 6,15,19,31-33 To determine whether the necrosis observed may be due to necroptosis, we determined whether RIPK1 and RIPK3 are expressed in clinical samples of RCC prior to organ culture, using adjacent histologically normal non-neoplastic kidney (NK) as controls. Sections of NK demonstrated normal intact tubules and remarkable glomeruli. In contrast, sections of RCC grades 1-4 demonstrated neoplastic morphology with increasing necrotic features, RCC grade 4 displaying extensive areas of necrosis, with nuclear material embedded within necrotic zones (Supplementary Figure 2). Remarkably, a strong homogenous expression of RIPK1 and RIPK3 in $>60 \%$ of cells was observed in high-grade tumors $(3 / 4)$, mainly confined to mTECs, and a few infiltrating MNCs and vascular endothelial cells (Figure 1C). In contrast, both proteins were detected only in MNCs within glomerular and interstitium in NK. Staining for RIPK1 was mainly cytoplasmic, whereas RIPK3 was cytoplasmic and nuclear. Immunoblotting of tissue lysates was concordant with IHC findings, showing a threefold to fourfold increase in both RIPK1 and RIPK3 expression in grade 3-4 RCC (Figure 1D, quantified in Figure 1E). No obvious difference in staining pattern was observed with all the RIPK1 and RIPK3 antibodies.

To determine whether TNF regulates expression of RIPK1 and RIPK3, and which receptor is involved, we treated organ cultures of NK and low-grade tumors (1/2), as these samples showed low levels of RIPK1 and RIPK3, with wtTNF, R1TNF or R2TNF. UT controls showed a rare signal for RIPK1 and RIPK3 in $<2 \%$ mTECs and infiltrating MNCs but a strong expression of RIPK1 and RIPK3 in $>60 \%$ of mTECs after treatment with R1TNF (Figure $2 a$ and Supplementary Figure 3). RIPK3 showed a cytoplasmic and nuclear pattern of staining, whereas RIPK1 was mainly cytoplasmic similar to the endogenous pattern found in $3 / 4$ grades RCC. Interestingly, R1TNF-induced marked upregulation of RIPK1 ( 5-fold) and RIPK3 ( 6-fold) in RCC compared with NK organ cultures ( 3-fold for RIPK1 and 3-fold for RIPK3) (Figures 2b and $c$ and Supplementary Figures $4 \mathrm{~A}$ and $4 \mathrm{~B}$ ). RIPK1 and RIPK3 mRNA were also induced by R1TNF mainly in mTECs (Figure 2a). For both assays and study groups, wtTNF treatment showed similar intensity and pattern of expression as R1TNF while R2TNF induced a weak to moderate signal (Supplementary Figure 3). No signal was detected in parallel sections when the primary antibody was pre-adsorbed with a blocking peptide prior to immunostaining or after gene knockdown experiments using human HEK293 cells, as described in the Methods section (Supplementary Figures $6 \mathrm{~A}$ and $6 \mathrm{~B})$. In addition, no signal was detected on sections hybridized with corresponding sense probes (data not shown). Taken together, these data suggest that TNF upregulates RIPK1 and RIPK3 expression in mTECs in RCC predominantly via TNFR1, and that this response is more pronounced in RCC compared with adjacent NK. For assessment of whether increased RIPK1 and RIPK3 expression was dependent on $\mathrm{NF}_{K} \mathrm{~B}$ activation, organ cultures were pretreated with pyrrolidine dithiocarbamate (PDTC), ${ }^{34}$ an inhibitor of NF $K \mathrm{~B}$ activation, before TNF treatment. TNF treatment does activate NF- $k \mathrm{~B}$ in tumor cells, as judged by increased levels of the phosphorylated form of the p65 subunit (NF-KBp65 ${ }^{\text {P-Ser276 }}$ ) and this was reduced by PDTC treatment. PDTC did not affect TNF induction of RIPK1 and RIPK3 expression in TECs (Supplementary Figures 7A and 7B). NFKB activation often protects cells from TNF-induced apoptosis through the induction of $\mathrm{C}$-FLIP, a protein that competes with caspase 8 for binding to FADD, a key step for autocatalytic caspase 8 activation. We observed TNF-induced activation of caspase $8^{\mathrm{p} 18}$ primarily in infiltrating leukocytes and only a weak infrequent signal in tumor cells. Interestingly, c-FLIP was present at high levels in untreated tumor cells and its expression levels are unaltered by TNF treatment (Supplementary Figure 8). These findings suggest that induction of RIPK1 and RIPK3 by TNF in TECs is independent of $\mathrm{NF}_{K} \mathrm{~B}$ and that constitutive overexpression of $\mathrm{C}-\mathrm{FLIP}$ in the 

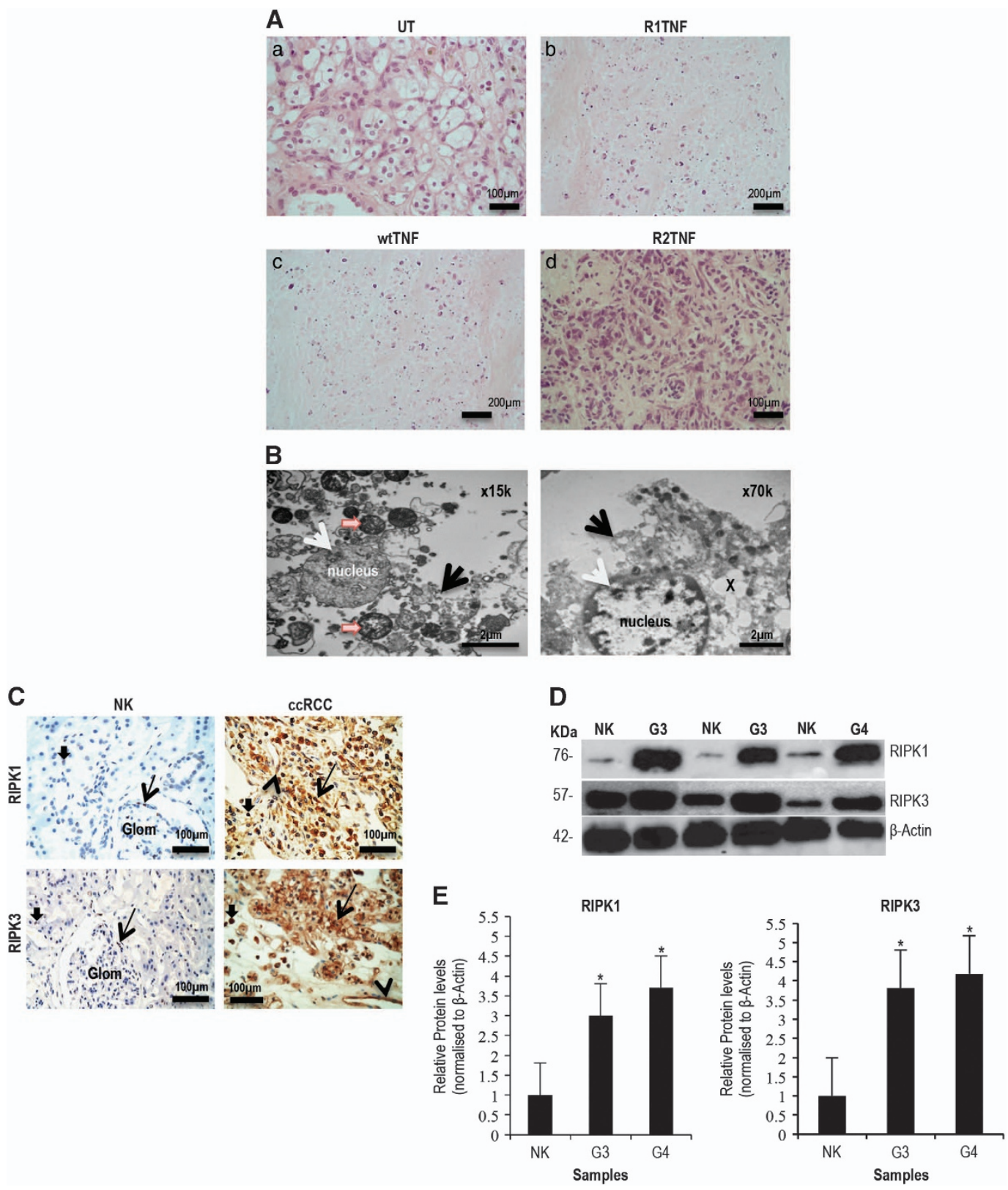

Figure 1 (A) Histology of untreated cultures (UT) show (a) low-grade RCC with small round tumor cells and a clear cytoplasm surrounded by a distinct cell membrane and round uniform nuclei with inconspicuous or absent nucleoli. (b) R1TNF- and (c) wtTNF-treated cultures show elevated level of death in mTECs compared with (d) R2TNF-treated cultures. (B) Morphological features of necrosis are evident in R1TNF-treated cultures such as large/small cytoplasmic vacuoles (x), condensation of the chromatin into small, irregular, circumscribed patches (white arrow), increasing translucent cytoplasm, swollen organelles (orange arrow) and disruption of the plasma membrane (black arrows). (C) Expression of RIPK1 and RIPK3 in tissue biopsies comprising RCC and NK; NK show a rare signal for RIPK1 and RIPK3 in MNCs within glomeruli (arrows) and with interstitium (small arrows). In contrast, RCC grade 3 shows marked signal in mTECs (arrows), MNCs (small arrows) and in some VECs (arrowheads). (D and E) Representative immunoblot of samples from nine patients with similar results and bar graph of relative RIPK1 and RIPK3 protein levels in grades 3/4 RCC (G3/G4) and non-tumor kidney (NK). Bars = mean+S.E.M.; ${ }^{*} P<0.05$ versus NK; paired Student's $t$-test. Glom-glomeruli; MNCs-mononuclear cells; TECs-tubular epithelial cells

tumor cells ${ }^{35,36}$ may confer resistance against caspase 8-induced apoptosis in RCC resulting in dominance of necroptotic cell death.

R1TNF activates signaling pathways associated with necroptosis in RCC. To determine whether downstream targets of RIPK3 are present and activated in organ cultures of RCC and NK in response to TNF, we examined the presence and phosphorylation of MLKL and Drp1. In UT controls, both RCC (Supplementary Figure 9) and NK (data not shown) showed strong expression of MLKL and Drp1 in mTECs and normal TECs as well as in infiltrating MNCs and some vascular endothelial cells. However, compared with UT controls, R1TNF increased the expression of phosphorylated MLKL at Ser358 (MLKL ${ }^{\text {Ser358) }}$ and phosphorylated Drp1 at Ser616 (pDrp1 ${ }^{\text {Ser616}}$ ) in RCC-mTECs by $\sim 5-10$-fold, and 
a
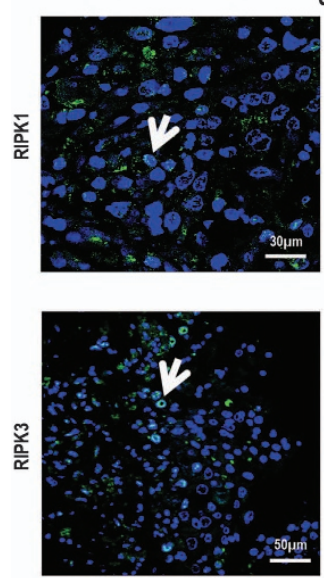

b
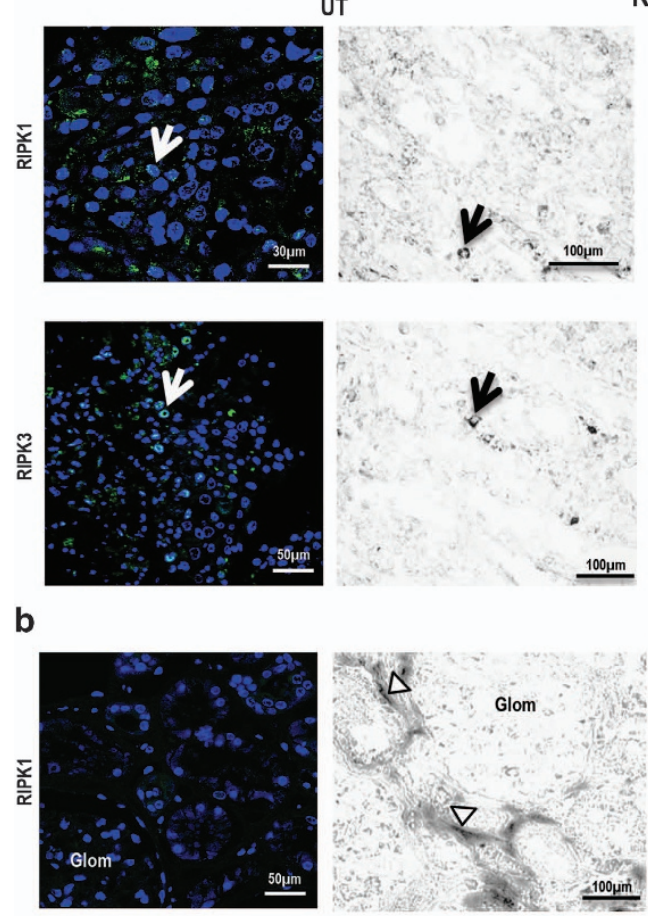

NK
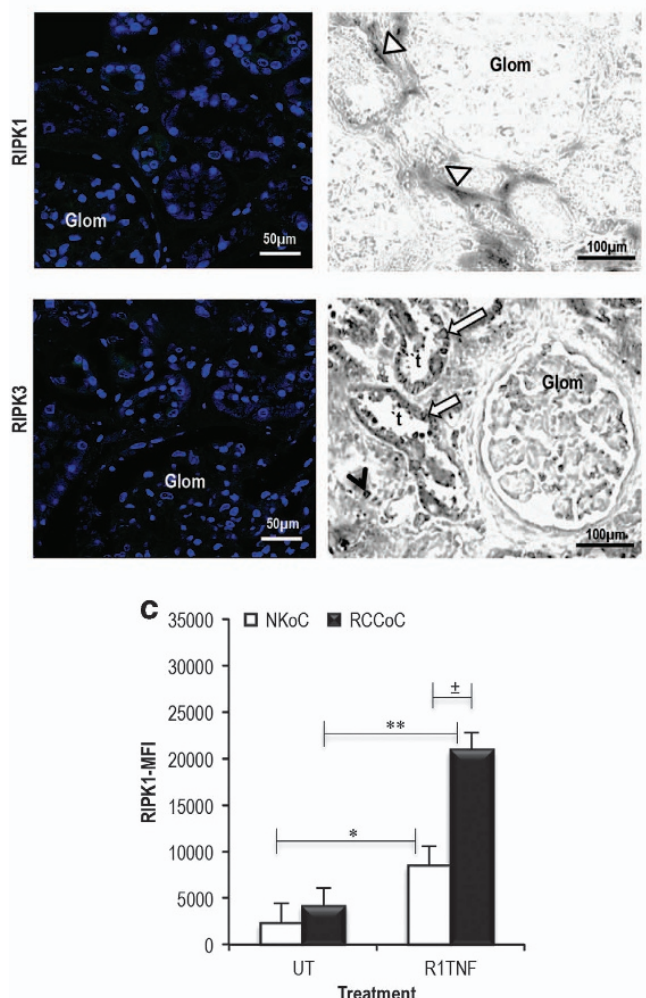

RCC
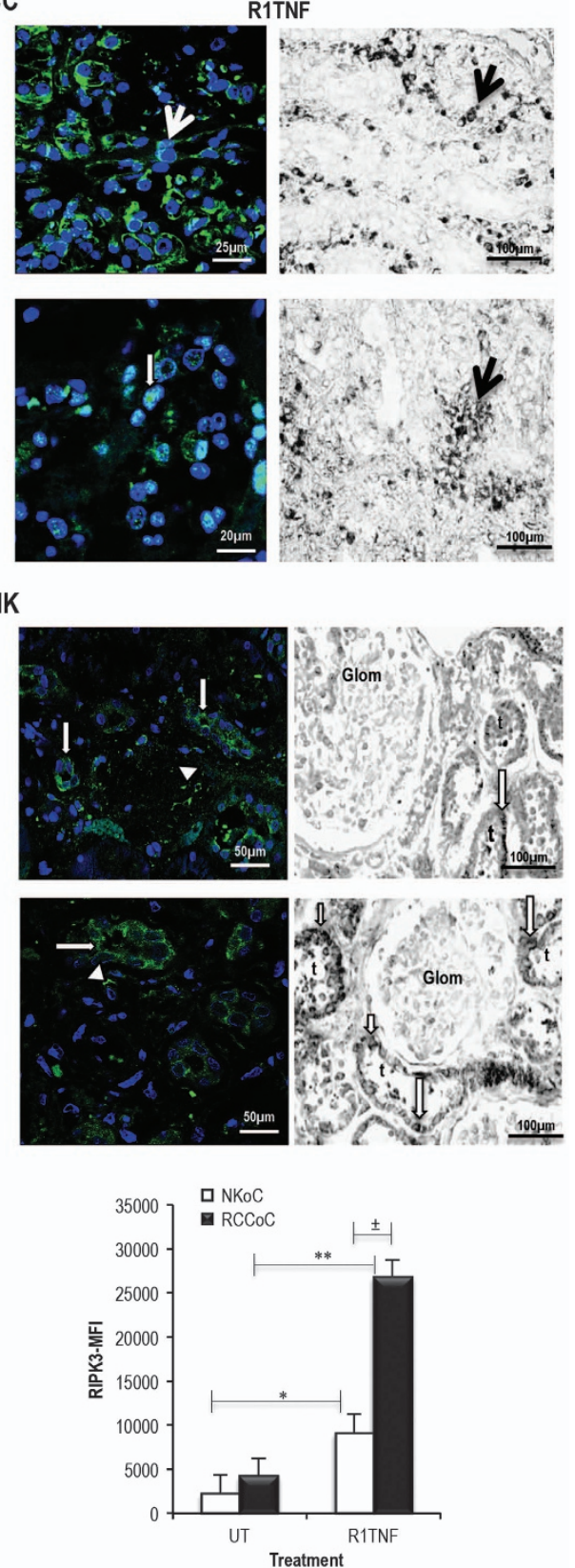

Figure 2 Representative confocal images and light micrographs of the effect of R1TNF on protein and mRNA expression for RIPK1 and RIPK3 in organ cultures of RCC grade 1 and adjacent non-tumor kidney (NK). (a and $\mathbf{b})$ Untreated (UT) cultures from RCC show a rare signal for RIPK1 and RIPK3 protein and mRNA. In contrast, R1TNF-treated cultures show a marked signal of both proteins mainly confined to mTECs (arrows), with RIPK3 also present in nuclei (white shaded arrow). Similarly, UT cultures of NK show a rare signal for both proteins; increased expression of both protein and mRNA is detected in R1TNF-treated cultures mainly confined to normal TECs (white arrows), peritubular capillaries (white arrowheads) and in infiltrating mononuclear cells (black arrowhead) but not in glomeruli (Glom). (c) Representative mean fluorescence intensity (MFI) for RIPK1 and RIPK3 expression in RCC and NK organ cultures. ${ }^{* *} P<0.01$ versus UT, ${ }^{*} P<0.05$ versus UT, ${ }^{ \pm} P<0.05$ versus R1TNF; Bars $=$ mean \pm S.E.M.; $n=3$ independent experiments from six separate organ culture experiments with similar results. Nuclei stained with Hoechst 33342 . Confocal images: $\times 40$ and $\times 63$ original magnifications; photomicrographs: $\times 400$ magnification

reduced pDrp1 at Ser637 (pDrp1 ${ }^{\text {Ser637) }}$ by $\sim 2$-fold (Figure 3a, quantified in Figure $3 b$ ). Cultures of NK showed a reduced response with about $\mathrm{a} \sim 2-3$-fold rise in $\mathrm{pMLKL} \mathrm{L}^{\text {ser358 }}$ and pDrp1 ${ }^{\text {ser616 }}$ and a similar reduction in pDrp $1^{\text {ser637 }}$ (quantified in Figure 3b). pMLKL ${ }^{\text {Ser358 }}$ was mainly diffusely cytoplasmic and nuclear, while pDrp1 $1^{\text {ser616 }}$ showed a cytoplasmic granular pattern (Figure 3c), consistent with Drp1 binding to mitochondria. Binding specificity for antibodies to MLKL, Drp1, pMLKL ${ }^{\text {Ser358, }}$, prp1 ${ }^{\text {Ser637 }}$ and pDrp1 ${ }^{\text {Ser616 }}$ was confirmed by incubation with a corresponding blocking peptide and by gene knockdown studies in human HEK293 cells (Supplementary Figures 10A and 10B). Indeed, immunogold 
a
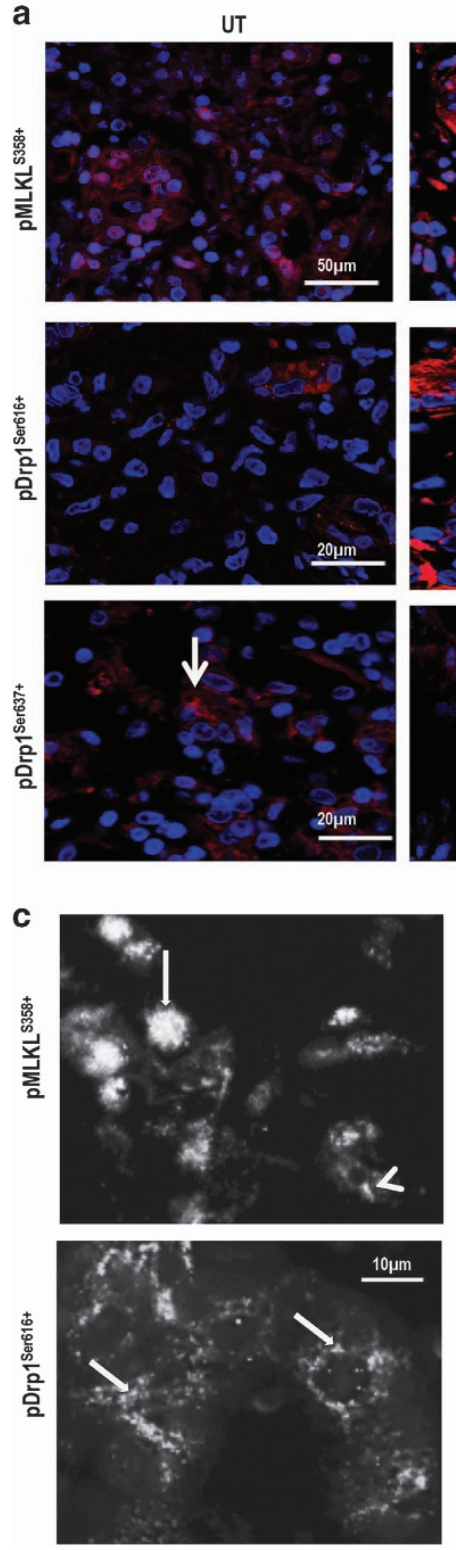
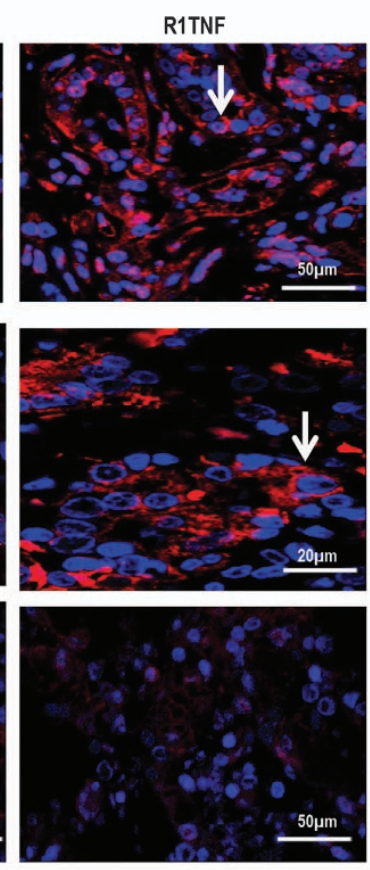

b
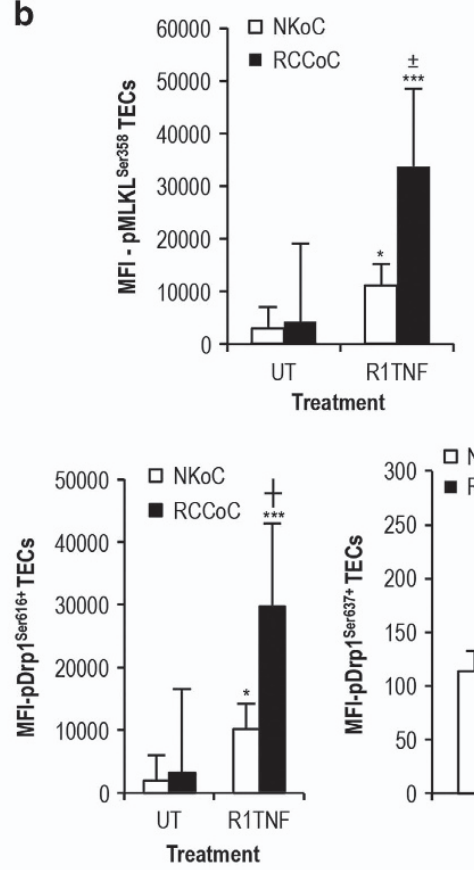
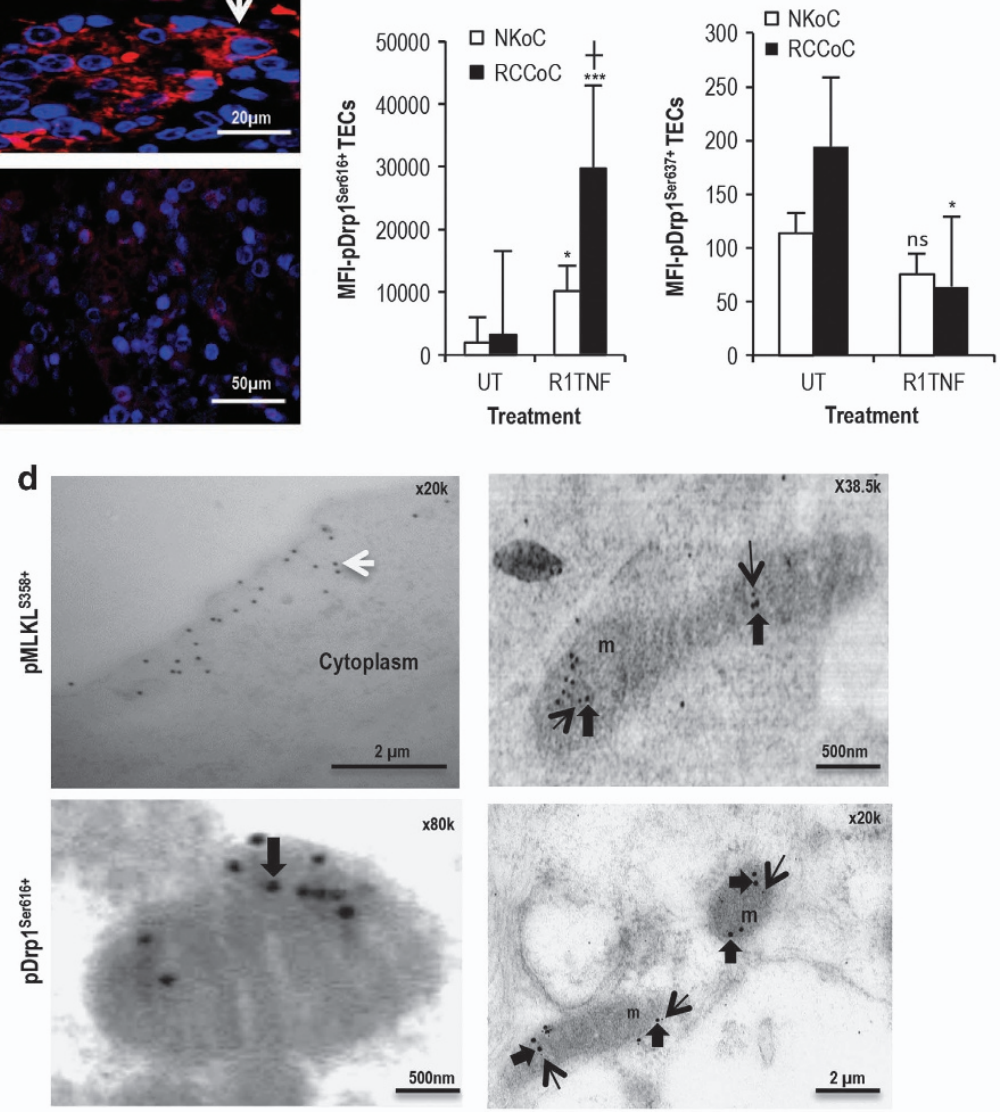

Figure 3 Effect of R1TNF on pMLKL ${ }^{\text {Ser358 }}$, pDrp1 ${ }^{\text {Ser616 }}$ and pDrp1 ${ }^{\text {Ser637 }}$ expression in organ cultures of RCC grade 1 and adjacent non-tumor kidney (NK). (a) R1TNF induced a marked expression of pMLKL ${ }^{\mathrm{S} 358}$ and pDrp1 ${ }^{\text {Ser616 }}$ but a reduced signal for pDrp1 ${ }^{\text {Ser637 }}$ compared with untreated controls (UT), with signal mainly confined to mTECs (arrows). (b) Quantification of the phosphorylated proteins in normal and mTECs presented as mean fluorescent intensity (MFI) shows a statistical significant difference between cultures. ${ }^{\star \star \star x} P<0.001$ versus $\mathrm{UT},{ }^{*} P<0.05$ versus UT; ${ }^{ \pm} P<0.05$ versus $\mathrm{R} 1 \mathrm{TNF}$ (NKoC); ${ }^{+} P<0.001$ versus R1TNF (NKoC); ns, not significant. (c) pMLKL Ser358 is seen within cytoplasm (arrowhead) and in some nuclei (arrow) (upper panel), while pDrp1 ${ }^{\text {Ser616 }}$ show cytoplasmic granular pattern (arrows) (lower panel). (d) Immunogold electron microscopy revealed pMLKL Ser358 $(15 \mathrm{~nm}$ particles) on the cell surface (black arrows), within cytoplasm (white arrow) and in mitochondria ( $\mathrm{m})$, while pDrp1 ${ }^{\text {Ser616 }}(5 \mathrm{~nm}$ particles, black arrow) was mainly confined to mitochondria $(\mathrm{m})$ (open arrows). Bars $=$ mean \pm S.E.M.; $n=3$ independent experiments from six separate organ culture experiments with similar results

electron microscopy of R1TNF-treated cultures showed pMLKL ${ }^{\text {Ser358 }}$ on the cell surface, within the cytoplasm and in some mitochondria, while pDrp $1^{\text {ser616 }}$ was mainly localized to mitochondria (Figure 3d). wtTNF induced comparable levels of signal for both phosphorylated proteins while the response with R2TNF in RCC was similar to that of UT controls (Supplementary Figure 11).

To evaluate whether TNF mediates an interaction between RIPK1 and RIPK3 and RIPK3 and pMLKL ${ }^{\text {ser358, we performed }}$ a proximity ligation assay (PLA) in organ cultures of RCC and NK (Figure $4 a$, quantified in Figures $4 b$ and $c$ ). R1TNF enhanced the RIPK1-RIPK3 interaction by about $\sim 10$-fold, evidenced by numerous strong red fluorescent spots within the cytoplasm of mTECs in RCC ( 60 PLA spots/cell) compared with UT controls ( 6 PLA spots/cell), whereas the interaction of RIPK1-RIPK3 induced by R1TNF in NK was only about 3-fold (quantified in Figure 4b). In addition, a fluorescent signal indicating a RIPK3-pMLKL ${ }^{\text {ser358 }}$ interaction increased 
by $\sim 5$-fold in mTECs in R1TNF-treated RCC cultures $(\sim 16$ PLA spots/cell) compared with UT ( 3 PLA spots/cell), whereas the increase in NK was about $\sim 2.5$-fold (quantified in Figure 4c). Data from wtTNF gave similar results as R1TNF, while R2TNF showed comparable data as UT controls (Supplementary Figures 12A-C).

To demonstrate that cells with higher pMLKL ${ }^{\text {Ser358, }}$ pDrp $1^{\text {Ser616 }}$ and lower pDrp $1^{\text {Ser637 }}$ are the cells that are prone
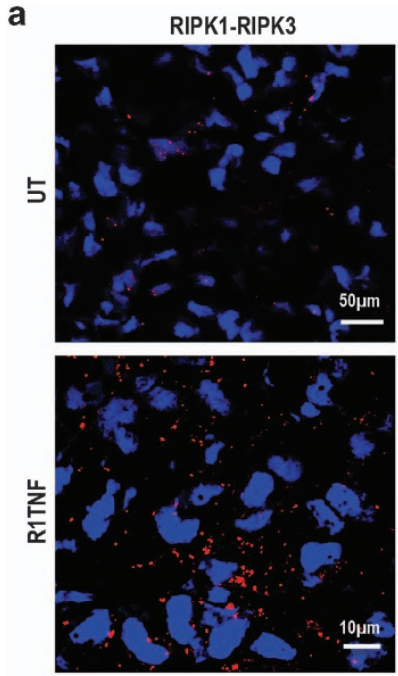

d
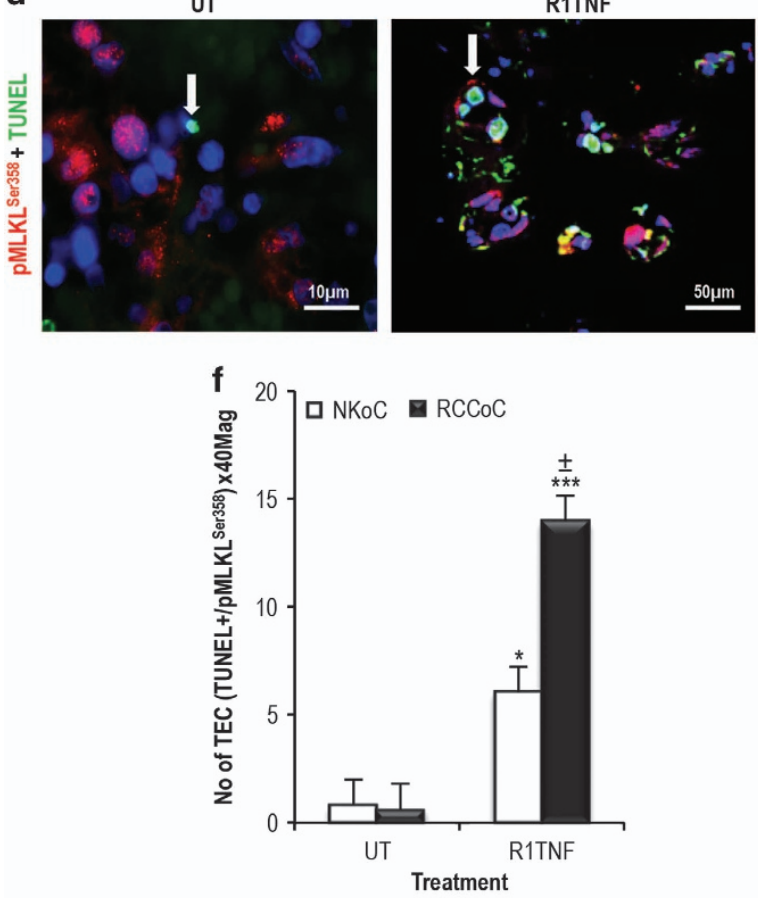

h

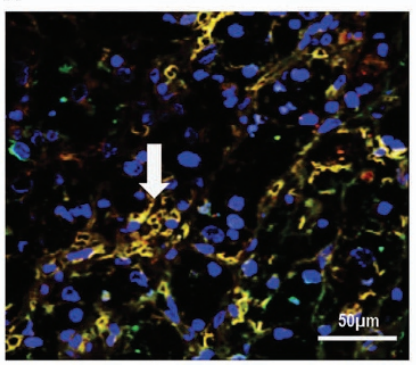

b

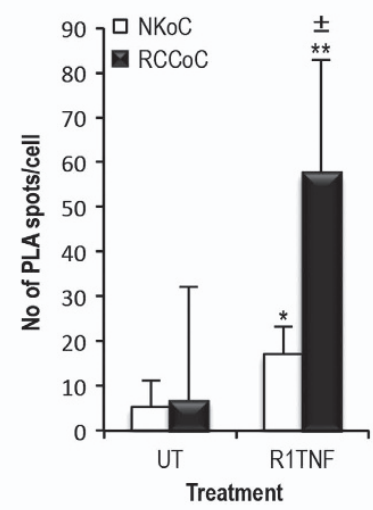

C RIPK3-pMLKL ${ }^{\text {Ser358 }}$

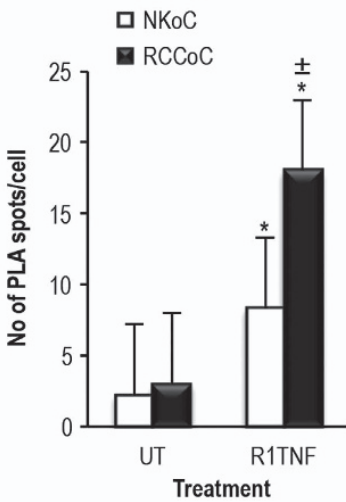

e
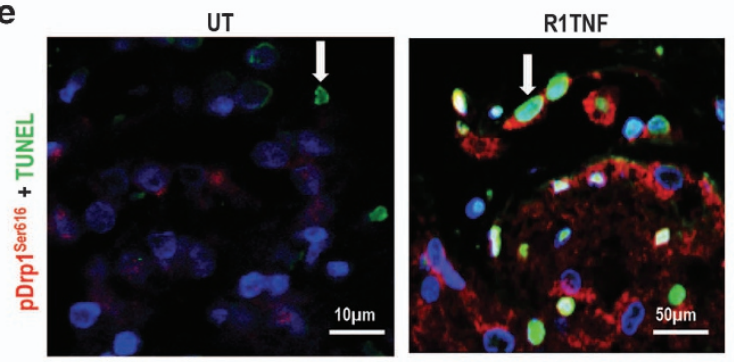

g

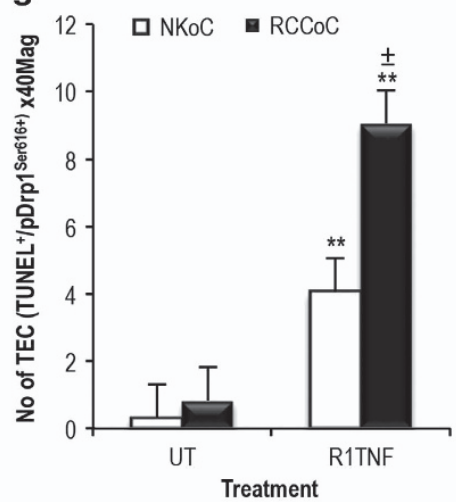

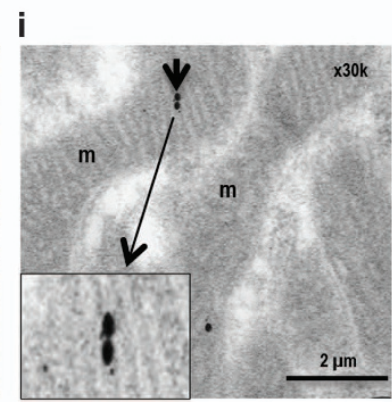


to die, we subjected all cultures to TUNEL in combination with IF for pMLKL ${ }^{\text {Ser358 }}$, pDrp $1^{\text {ser616 }}$ and pDrp1 $1^{\text {Ser637. We found a }}$ significant $>60 \%$ association between $\mathrm{pMLKL}^{\text {ser358 }}$ and

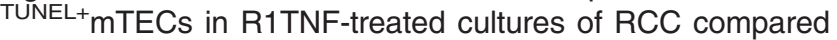
with UT controls $(<2 \%)$, which showed fewer numbers of ${ }^{\text {TUNEL+ }}{ }^{m T E C S}$ and no association with pMLKL ${ }^{\text {Ser358 }}$ (Figure 4d, quantified in Figure 4f). An association of $>40 \%$ between pDrp $1^{\text {Ser616 }}$ and ${ }^{\text {TUNEL+ }}$ mTECs was also detected in R1TNF-treated RCC organ cultures (Figure 4e, quantified in Figure 4g, Table 1). wtTNF showed similar findings to R1TNF. Although R2TNF also increased pMLKL $\mathrm{Ser}^{58}$ in some ${ }^{\text {TUNEL+ }}{ }^{m}$ TECs, it was not significant compared with UT controls (Supplementary Figure 13A, quantified in Supplementary Figures $13 \mathrm{~B}$ and $13 \mathrm{C}$ ). To determine whether pDrp1 ${ }^{\text {Ser616 }}$ co-localizes with pMLKL ${ }^{\text {Ser358 }}$ in mTECs, we costained for pDrp1 ${ }^{\text {Ser616 }}$ and $\mathrm{pMLKL}{ }^{\text {Ser358 }}$ in organ cultures of RCC cells treated with R1TNF and demonstrated a moderate association (>20\%) (Figure $4 \mathrm{~h}$ ) confirmed by immunogold EM showing staining in mitochondria (Figure 4i). Similar, but much reduced, effects of R1TNF on necrotic cell death and associated signaling pathways were evident in TECs in NK (quantified in Supplementary Figures 13B-C).

Inhibitors of apoptosis and necroptosis differentially prevent TNF-mediated cell death in RCC organ cultures. To further define the TNF-mediated cell death pathway in RCC, we utilized specific inhibitors. Cultures were treated with zVAD.fmk, a pan-caspase inhibitor, ${ }^{37}$ or necrostatin-1 (Nec-1), an inhibitor of RIPK1 kinase activity, and cell death was quantified on TUNEL stained sections. ${ }^{8}$ zVAD.fmk inhibited cell death by $\sim 10 \%$, whereas Nec- 1 by about $\sim 40-60 \%$ (Figure 5A, quantified in Figure 5B). The combination of Nec-1 and zVAD.fmk was additive, indicating that apoptosis and necrosis occur in separate cells (Table 2). R2TNF also induced death of mTECs but to a lesser extent than R1TNF, with no significant inhibition by zVAD.fmk, and a small but significant inhibition with Nec-1. Similar but less marked effects were observed in NK (Table 2).

Next, we determined whether inhibition of cell death by zVAD.fmk or Nec-1 or their combination correlates with R1TNF-mediated phosphorylation of MLKL ${ }^{\text {Ser358 }}$ and

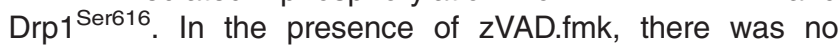
obvious reduction in the expression of the phosphorylated proteins although there was a mild decrease in the number of ${ }^{\text {TUNEL+}}{ }^{m}$ TECS associated with pMLKL ${ }^{\text {Ser358 }}$ and pDrp1 ${ }^{\text {Ser616 }}$ $(\sim 14 \%)$ (Figures $5 \mathrm{C}$ and $\mathrm{D}$, quantified in Figure $5 \mathrm{E})$. In

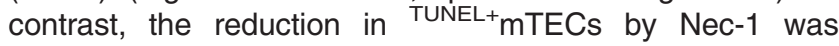
associated with a diminished level of both phosphorylated proteins ( 3-fold), comparable with that found in cultures treated with a combination of zVAD.fmk and Nec-1. Thus, the decrease in the level of MLKL ${ }^{\text {Ser358 }}$ and Drp1 ${ }^{\text {Ser616 }}$ are strongly correlated with the decrease in ${ }^{\text {TUNEL+ }}{ }^{m T E C}$ s only after treatment of $\mathrm{Nec}-1$ and not zVAD fmk, indicating that the necrosis is not secondary to apoptosis.

To test whether pMLKL ${ }^{\text {Ser358 }}$ has a functional role in TNF-mediated death of mTECs in RCC, we applied NSA, which blocks programmed necrosis by specifically targeting MLKL. ${ }^{15}$ The number of R1TNF-induced TUNEL+ ${ }^{\text {TTECs was }}$ reduced by NSA treatment in a concentration-dependent manner (Figure 6a, quantified in Figure 6b) (UT $\sim 5 \%$, R1TNF 75\%; R1TNF+50 $\mu \mathrm{M}$ NSA $15 \%$; R1TNF+20 $\mu \mathrm{M}$ NSA $\sim 30 \% ; \quad$ R1TNF+10 $\mu \mathrm{M} \quad \mathrm{NSA} \sim 35 \% ; \quad \mathrm{R} 1 \mathrm{TNF}+5 \mu \mathrm{M}$ NSA $~ 70 \%$ ). A similar but reduced effect of NSA was evident in NK organ cultures (data not shown). NSA inhibition of mTEC death correlated with a concentration-dependent reduction of pMLKL ${ }^{\text {ser358 }}$ expression (Figure 6c). wtTNF (without NSA)

Table 1 Expression of necrosomal signaling components regulated by wtTNF, R1TNF and R2TNF in malignant tubular epithelial cells in human RCC grade 1 organ cultures

\begin{tabular}{|c|c|c|c|c|c|c|}
\hline & UT & wtTNF & R1TNF & R2TNF & Subcellular localization & Pattern of immunostaining \\
\hline RIPK1 & $+1-$ & ++++ & ++++ & $+1-$ & Cytoplasmic & Diffuse \\
\hline RIPK3 & $+1-$ & ++++ & ++++ & + & Cytoplasmic/nuclear & Diffuse \\
\hline Total MLKL & ++++ & ++++ & ++++ & + & Cytoplasmic & Diffuse \\
\hline pMLKL Ser358 & $+1-$ & ++++ & ++++ & + & Cytoplasmic/nuclear & Diffuse/punctate \\
\hline Total Drp1 & ++++ & +++ & +++ & + & Cytoplasmic & Diffuse \\
\hline pDrp1 ${ }^{\text {Ser616 }}$ & - & +++ & +++ & + & Cytoplasmic & Punctate \\
\hline pDrp1 ${ }^{\text {Ser637 }}$ & ++ & $+1-$ & $+1-$ & + & Cytoplasmic & Punctate \\
\hline
\end{tabular}

Abbreviations: pMLKL ${ }^{\text {Ser358 }}$, phosphorylated MLKL at Ser358; pDrp1 ${ }^{\text {Ser616 }}$, phosphorylated Drp1 at Ser616 and pDrp1 ${ }^{\text {Ser637 }}$-phosphorylated at Ser637; RIPK1, receptor-interacting protein kinase 1 ; RIPK3, receptor-interacting protein kinase 3; Scores: - no labeling; +l - occasional positive labeling (>2\%); + weak labeling $(>5 \%) ;++$ intermediate labeling $(>10 \%) ;+++$ strong labeling $(>40 \%) ;++++$ very strong labeling $(>60 \%)$.

Figure 4 PLA of organ culture of RCC grade 1. (a) In comparison with untreated controls (UT), R1TNF induced a strong interaction of RIPK1-RIPK3 and RIPK3-pMLKL Ser358 appearing as strong red fluorescence spots mainly within the cytoplasm of mTECs. Each individual interacting protein pair observed as a red spot by confocal microscopy is expressed as the number of signals/cell (PLA spots/cell). (b and c) Quantification of PLA spots in TECs in the two study groups; RCC (RCCoC) and normal kidney (NKoC) show a statistically significant difference, more pronounced in RCCoC. ${ }^{\star *} P<0.01$ versus UT, ${ }^{*} P<0.05$ versus UT, ${ }^{ \pm} P<0.05$ versus R1TNF (NKoC). (d and e) Representative confocal images of pMLKL ${ }^{\text {Ser358 }}$ or pDrp1 ${ }^{\text {Ser637 }}$ and TUNEL in organ cultures of RCC grade 1. Compared with UT cultures, R1TNF induced an increase in the level of ${ }^{\text {TUNEL+}}{ }^{2} \mathrm{mTECs}$

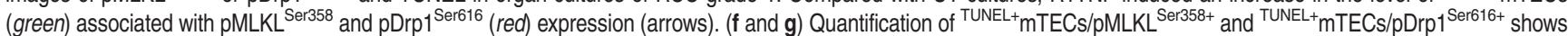
statistical significant differences between cultures. ${ }^{* * *} P<0.0001$ versus UT, ${ }^{* \star} P<0.001$ versus UT, ${ }^{*} P<0.01$ versus UT, ${ }^{ \pm} P<0.05$ versus R1TNF (NKoC). (h) Combined immunofluorescence of R1TNF-treated cultures shows co-localization of pMLKL ${ }^{\text {Ser358 }}$ and pDrp $1^{\text {Ser616 }}$ in mTECs (arrow). (i) Immunogold electron microscopy demonstrate close proximity of gold particles for pMLKL ${ }^{\text {Ser358 }}(5 \mathrm{~nm})$ and $\mathrm{pDrp1}^{\text {Ser616 }}(15 \mathrm{~nm})$ in mitochondria $(\mathrm{m})$ (inset zoomed $\left.\times 2.5\right)$. Bars $=$ mean \pm S.E.M.; images are representative of $n=3$ independent experiments from six separate organ culture experiments with similar results 


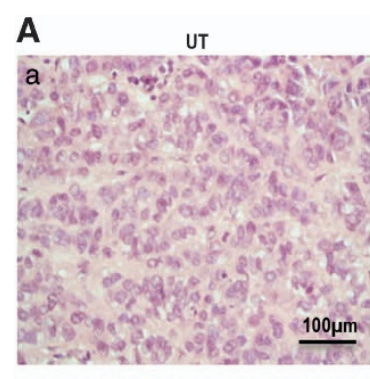

R1TNF+n

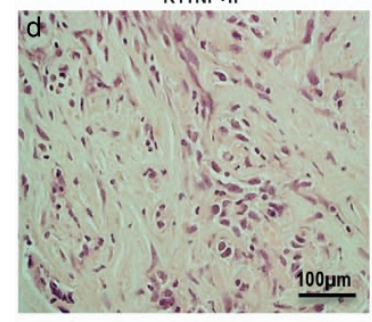

C

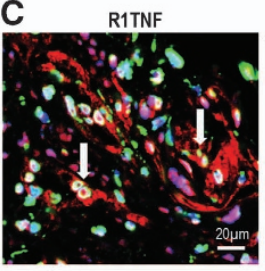

R1TNF+n

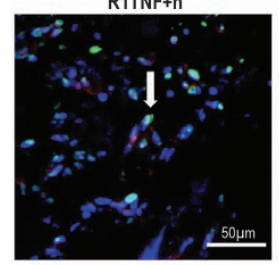

D

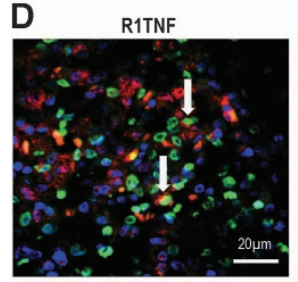

R1TNF+n

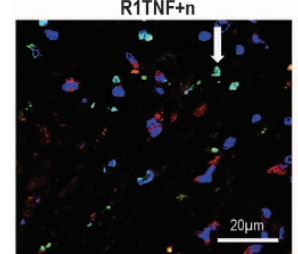

R1TNF

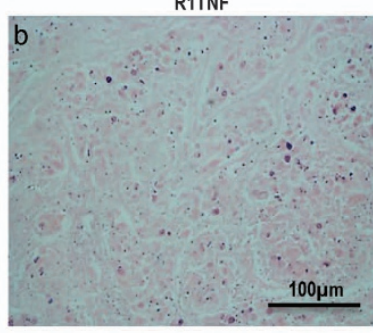

R1TNF+n+z

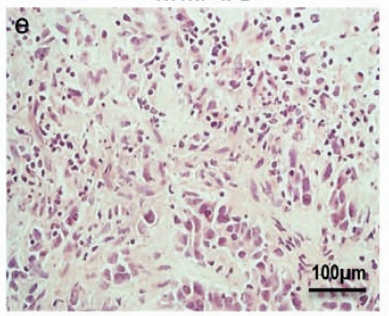

R1TNF+Z

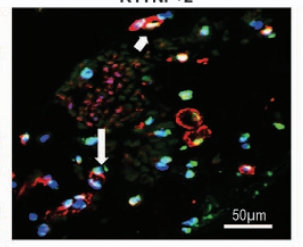

R1TNF+z+n

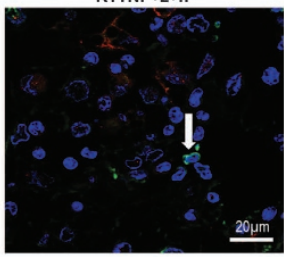

R1TNF+z

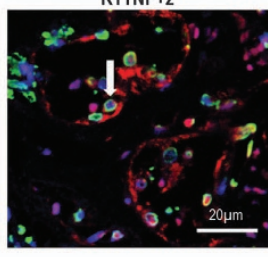

R1TNF+z+n

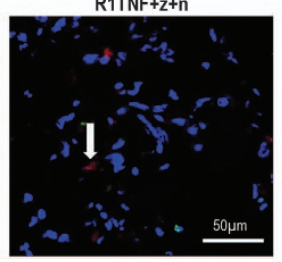

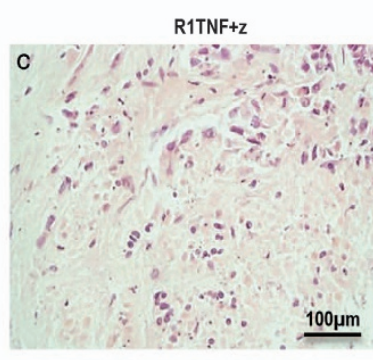

$\mathbf{B}_{90} \mathrm{INKOC}^{\mathrm{B}} \mathrm{RCCOC}$

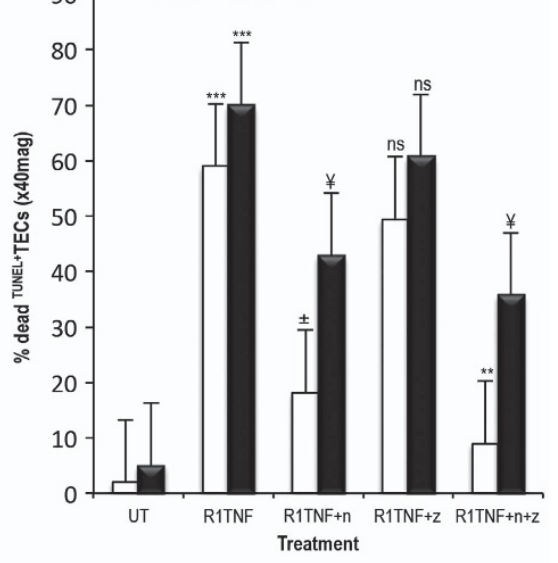

$\mathbf{E}_{20}$

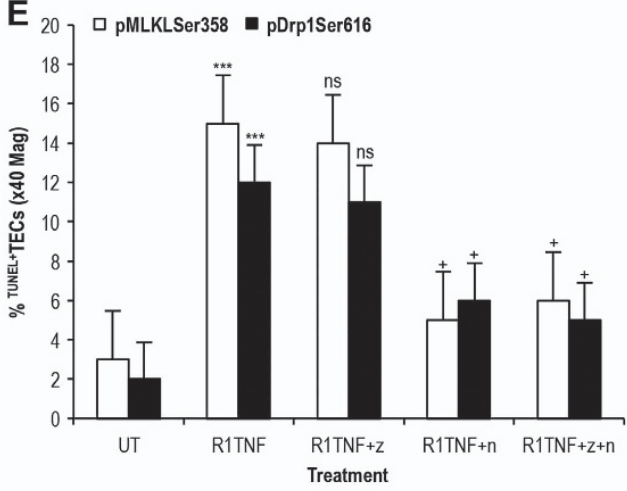

Figure 5 (A) Representative hematoxylin and eosin-stained sections demonstrate morphological features of necrosis in organ cultures of grade $1 \mathrm{ccRCC}$ treated with or without necrostatin-1 or/and zVAD.fmk followed by R1TNF. R1TNF induced increased cell death compared with untreated (UT) cultures (a and b). Treatment with zVAD.fmk (z) (c) resulted in partial inhibition of cell death, further rescued by necrostatin-1 $(n)(d)$, even more so by a combination of $z$ and $n(e)$. (B) Quantification of parallel sections stained with TUNEL show the precentage of dead tubular epithelial cells (TECs) in 10 random high power fields at $\times 40$ magnification. ${ }^{* t *} P<0.0001$ versus UT; ** $P<0.001$ versus R1TNF+n

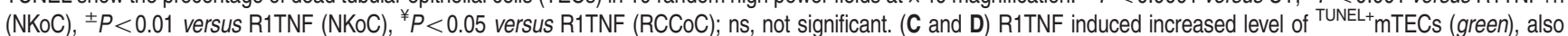
expressing pMLKL ${ }^{\text {Ser358 }}$ or pDrp1 ${ }^{\text {Ser616 }}$ (arrows) (red). Treatment with zVAD.fmk (z) partially reduced the number of ${ }^{\text {TUNEL+ }}{ }^{m T E C s}$ (arrows) but did not have any effect on pMLKL ${ }^{\text {Ser358 }}$ or pDrp1 ${ }^{\text {Ser616 }}$ expression. In contrast, treatment with necrostatin-1 (n) resulted in a significant reduction in the number of ${ }^{\text {TUNEL+ }}{ }^{m T E C s, ~ a s s o c i a t e d ~ w i t h ~ a ~}$ diminished level of pMLKL ${ }^{\text {Ser358 }}$ or pDrp1 ${ }^{\text {Ser616 }}$ comparable with cultures treated with a combination of zVAD.fmk and necrostatin-1 (z+n) (arrows). (E) Quantification of the percentage of ${ }^{\text {TUNEL }}{ }^{+}$mTECs in combination with pMLKL ${ }^{\text {Ser358 }}$ or pDrp $1{ }^{\text {Ser616 }}$ in 10 random high power fields at $\times 40$ magnification; ${ }^{* * x} P<0.001$ versus UT; ${ }^{+} P<0.05$ versus R1TNF; ns, not significant. Bars $=$ mean \pm S.E.M. Images are representative of $n=3$ independent experiments from six separate organ culture experiments with similar results 
TNFR1-induced necroptosis in tubular cells in RCC

RS Al-Lamki et al

Table 2 Percentage of TNF-mediated cell death of tubular epithelial cells in human RCC grade 1 and adjacent non-tumor kidney (NK) organ cultures subjected to TUNEL

\begin{tabular}{|c|c|c|c|c|c|c|}
\hline \multirow[b]{2}{*}{ Treatment } & \multicolumn{3}{|c|}{ RCCoC } & \multicolumn{3}{|c|}{ NKoC } \\
\hline & wtTNF & R1TNF & R2TNF & wtTNF & R1TNF & R2TNF \\
\hline $\begin{array}{l}\text { UT } \\
\text { alone } \\
+n \\
+z \\
+n+z\end{array}$ & $\begin{array}{l}4.60 \pm 0.13^{* \star \star} \\
72.0 \pm 0.11^{+} \\
39.1 \pm 0.31^{+} \\
62.0 \pm 0.40^{+} \\
28.1 \pm 0.17^{\star \star}\end{array}$ & $\begin{array}{l}5.1 \pm 0.10^{\star \star \star \star} \\
70.2 \pm 0.12^{+} \\
42.8 \pm 0.21^{+} \\
60.7 \pm 0.07^{+} \\
35.7 \pm 0.32^{\star \star}\end{array}$ & $\begin{array}{l}4.5 \pm 0.3 \\
7.0 \pm 0.2^{*} \\
5.2 \pm 0.3^{+} \\
6.5 \pm 0.3 \\
5.0 \pm 0.2\end{array}$ & $\begin{array}{l}2.7 \pm 0.3^{\star \star \star} \\
61.0 \pm 0.6^{\star \star \star} \\
41.1 \pm 0.3^{+} \\
52.3 \pm 0.70^{\mp} \\
36.1 \pm 0.17^{\#}\end{array}$ & $\begin{array}{l}2.2 \pm 01 \\
59.1 \pm 0.1^{\star \star \star} \\
28.1 \pm 0.34^{+} \\
47.4 \pm 0.1^{¥} \\
21.3 \pm 0.21^{\#}\end{array}$ & $\begin{array}{l}2.1 \pm 0.16 \\
5.0 \pm 0.12^{*} \\
3.2 \pm 0.15^{\dagger} \\
4.1 \pm 0.47 \\
3.0 \pm 0.23\end{array}$ \\
\hline
\end{tabular}

Abbreviations: n, necrostatin-1 (10 $\mu \mathrm{M})$; NKoC, normal kidney organ culture; RCCoC, RCC organ culture; z, zVAD.fmk (20 $\mu \mathrm{M}) ; \mathrm{n}+\mathrm{z}$ (necrostatin-1 + zVAD.fmk); UT, Untreated. wtTNF $(10 \mathrm{ng} / \mathrm{ml}), \mathrm{R} 1 \mathrm{TNF}$ and R2TNF $(1 \mu \mathrm{g} / \mathrm{ml})$ were used. Percentage represents mean $\pm \mathrm{S}$.E.M. $(n=6) ;{ }^{* \star} P<0.0001,{ }^{\star} P<0.001 \mathrm{vers}(\mathrm{s}) \mathrm{UT} ;{ }^{+} P<0.001$, ${ }^{+} P<0.01$ versus wtTNF and R1TNF, ${ }^{+} P<0.05$ versus R2TNF; ${ }^{*} P<0.05$ versus wtTNF or R1TNF $(\mathrm{NKoC}) ;{ }^{* *} P<0.05$ versus wtTNF+N $(\mathrm{RCCoC}) ;{ }^{\#} P<0.05$ versus wtTNF or R1TNF (NKoC).

induced comparable levels of death in mTECs as R1TNF with similar inhibitory effects of NSA (data not shown). R2TNF induced an insignificant increase in MTEC death as compared with UT controls.

To investigate the importance of pDrp1 in TNF-mediated death of mTECs in RCC, we used mdivi-1, a small molecule inhibitor of Drp1. ${ }^{38-40}$ Treatment of organ cultures with mdivi-1 inhibited wtTNF- and R1TNF-mediated alterations in the phosphorylation status of Drp1, and reduced increases in ${ }_{\text {TUNEL+ }}$ mTECs, which was further reduced by treatment with a combination of mdivi-1 and Nec-1 (Figure 6d, quantified in Figure 6e) (UT 5\%; R1TNF 72\%; R1TNF+m 48\%; $\mathrm{R} 1 \mathrm{TNF}+\mathrm{m}+\mathrm{n} \sim 22 \% ; \quad \mathrm{R} 1 \mathrm{TNF}+\mathrm{m}+\mathrm{z} \sim 45 \% ; \quad \mathrm{R} 1 \mathrm{TNF}+\mathrm{m}+\mathrm{n}$ $+Z \sim 21 \%$ ). mdivi-1 inhibition of mTEC death correlated with a significant reduction of pDry $1^{\text {Ser616 }}$ and pDrp1 $1^{\text {Ser637 }}$ (Figures $6 f$ and $6 \mathrm{~g}$ ). Similar effects of wtTNF and R1TNF-induced ${ }^{\text {TUNEL+}}{ }^{m}$ TECs were observed in NK organ cultures but to a lesser extent than in RCC organ cultures (data not shown).

\section{Discussion}

TNF was initially described as a factor present in the blood of Bacillus Calmette-Guerin-infected mice treated with endotoxin ${ }^{41,42}$ where it was shown to be an important mediator of the priming phase of a Shwartzman-like reaction involving neutrophil activation and intravascular coagulation. ${ }^{43}$ Vascularized tumors showed evidence of hemorrhagic necrosis, hence the name TNF. Various in vitro studies later reported that in most cultured tumor cells, TNF caused apoptotic cell death, ${ }^{4,45}$ although there were some exceptions that appeared to show death with features of necrosis (e.g., L929 cells). ${ }^{46}$ The relationship between tumor cell apoptosis in vitro and necrosis in vivo was not clear. However, in the last few years, it has been appreciated that features of necrosis can also be induced in individual cells in culture $6,7,18,23,47$ and TNF-induced necrosis, like apoptosis, is thought to be predominantly mediated by TNFR 1 signaling. ${ }^{2}$ Which form of programmed death predominates in situ is open to debate. Our study is unique in that it is based on an organ culture system so that cells are studied in situ but death cannot be attributed to Shwartzman-type phenomena. Thus, necroptosis and indirectly caused necrosis can be separated and this may be the first example in which this approach has been used.
In vitro studies have utilized antibodies to localize distinct proteins that participate in TNF-induced necroptosis and changes in their phosphorylation status. ${ }^{23,48}$ We have taken advantage of the pharmacological inhibitors of these proteins to monitor cell death combined with immunohistochemistry at the light and electron microscopic level to determine the effect (s) of TNF in RCC and NK. Consistent with our earlier report, ${ }^{27}$ we show morphological evidence of death in mTECs of RCC cultures treated with wtTNF and R1TNF, and to a minor extent TNFR2. This was associated with upregulation of RIPK1 and RIPK3 mRNA and protein expression, kinases involved in TNF-mediated necroptosis. ${ }^{2,6,10,33,49-53}$ We further show a significantly elevated RIPK1 and RIPK3 protein expression in mTECs of high grade (3/4) as compared with low-grade tumors (1/2). Upregulation of RIPK1 has been reported in lung cancer and glioblastoma tissues, ${ }^{54,55}$ but not in colon cancer, ${ }^{52}$ suggesting that distinct mechanisms of cell killing may exist in different tumor types. Inhibition of $\mathrm{NF}_{K} \mathrm{~B}$ by PDTC did not abolish TNF-induced RIPK1 and RIPK3 in our organ cultures suggesting that activation of these kinases occurs independent of $\mathrm{NF} K \mathrm{~B}$, in line with O'Donnell et al., ${ }^{56}$ who reported that K63-linked ubiquitination of RIPK1 occurs early after TNFR1 stimulation and does not require NF $\kappa$ B transcription. In RCC, it is possible that the higher expression of RIPK1/3 renders them more prone to TNF-mediated necroptosis, suggesting that differential treatments may be devised to augment chemotherapeutic death in RCC while sparing normal surrounding tissue. Our observation of the small amount of TNFR2-mediated death of mTECs is consistent with a proposal by Chan et al. ${ }^{11}$ that TNFR2 signaling does not directly engage the cell death machinery, but rather enhances TNF-induced necroptosis indirectly via TNFR 1 by recruitment of RIPK1. ${ }^{11}$ If TNFR1 is activated by TNFR2 in RCC independently of TNFR1 occupancy, it is a very minor response.

In the next steps, we underpinned the necroptotic pathway by demonstrating a direct interaction between RIPK1 and RIPK3, between RIPK3 and MLKL, and the participation of MLKL and Drp1 in the necrotic process, as outlined in the scheme shown in Figure 6h. Previous work has shown that RIPK3 is recruited to RIPK1 through their RHIM domains upon execution of necrosis. ${ }^{7,11,15,52}$ The pharmacological inhibition of RIPK1 abolishes the recruitment of RIPK3 and thereby inhibits RIPK3 activation, suggesting that RIPK1 is upstream 
a
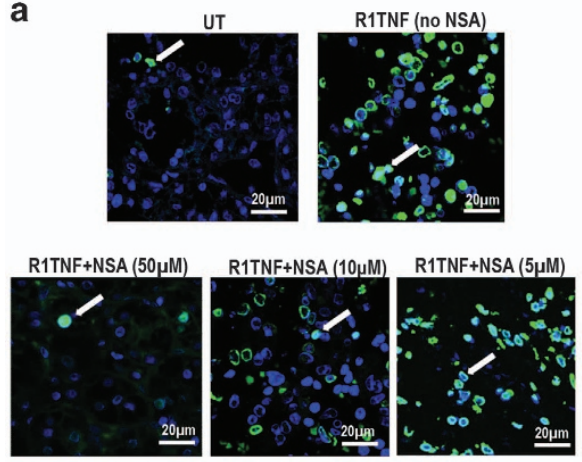

d UT

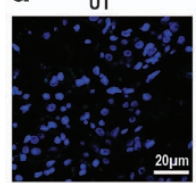

R1TNF+m+n
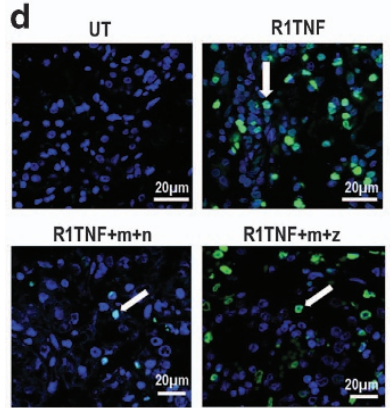

R1TNF+m+z
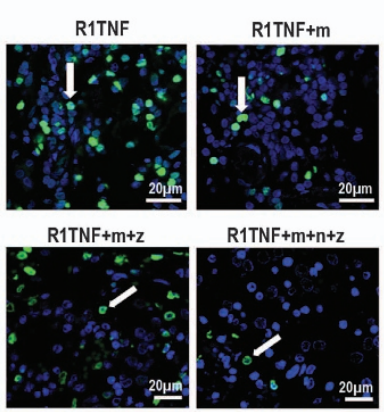

R1TNF+m+n+z

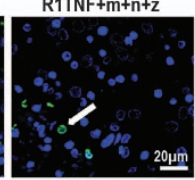

\section{b}

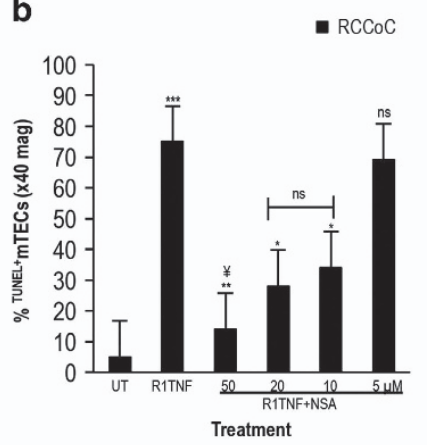

e

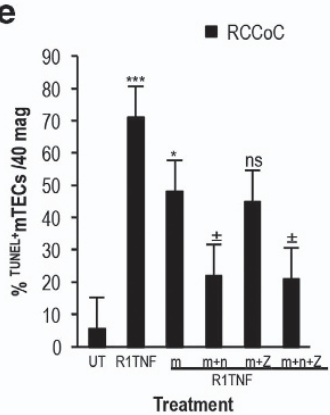

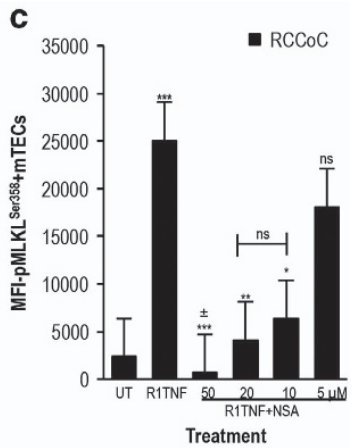

f

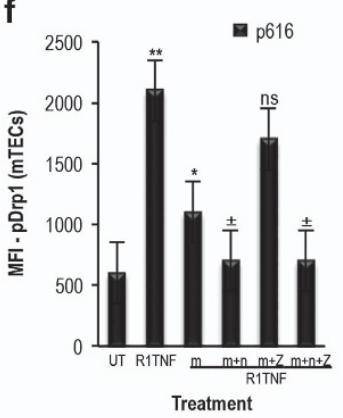

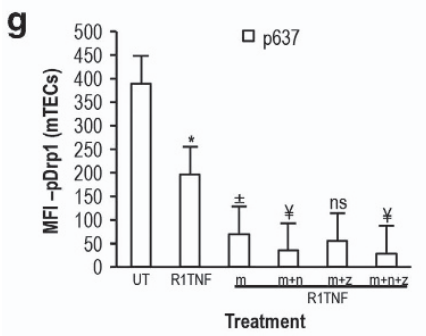

h

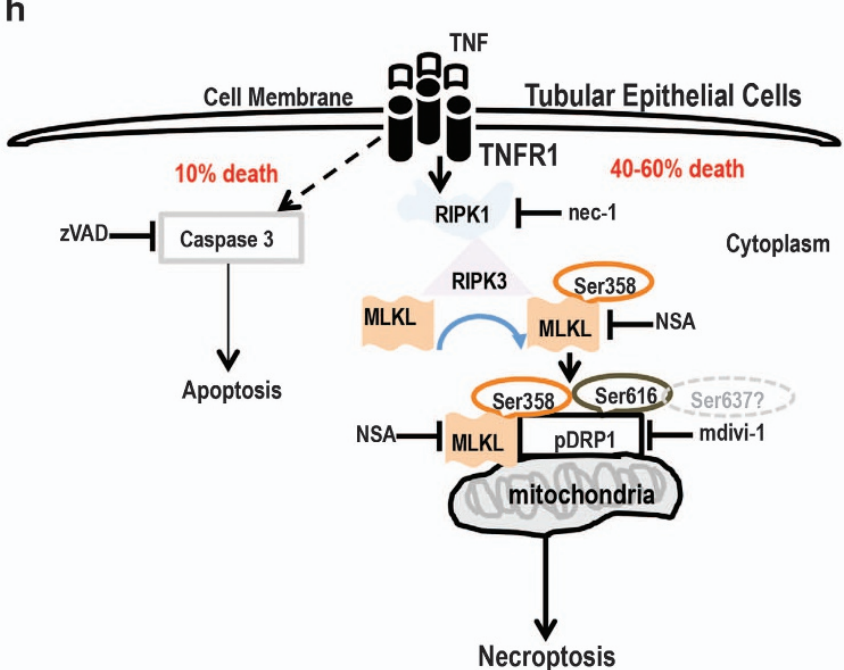

Figure 6 (a) Effect of necrosulfonamide (NSA) and mdivi-1 $(\mathrm{m})$ in grade 1 RCC organ cultures treated with R1TNF. R1TNF alone without NSA (no NSA) induced increased levels of ${ }^{\mathrm{TUNEL}}{ }^{+} \mathrm{mTECs}$, which were significantly reduced with $50 \mu \mathrm{M}$ NSA, and to a lesser extent, with $10 \mu \mathrm{M}$ or $20 \mu \mathrm{M}$ NSA (arrows). Cultures pretreated with $5 \mu \mathrm{M}$ NSA showed comparable levels of ${ }^{\text {TUNEL }}{ }^{+} m T E C s$ as untreated cultures (UT). (b) The percentage of ${ }^{\text {TUNEL }}{ }^{+} m T E C s$ and (c) pMLKL ${ }^{\text {Ser358 }}$ expression presented as mean fluorescent intensity (MFI) in similar cultures. ${ }^{* * *} P<0.0001$ versus $\mathrm{UT},{ }^{* *} P<0.001$ versus R1TNF; ${ }^{*} P<0.05$ versus R1TNF; ${ }^{*} P<0.05$ versus $\mathrm{R} 1 \mathrm{TNF}(+20$ or $10 \mu \mathrm{M}) ;{ }^{ \pm} P<0.001$ versus $\mathrm{R} 1 \mathrm{TNF}(+20$ or $10 \mu \mathrm{M}$ ); ns, not significant. (d) In comparison with UT, which show a rare ${ }^{\text {TUNEL+}}{ }^{+}$mTECs, R1TNF alone (without $\mathrm{m}$ ) induced increased levels of ${ }^{\text {TUNEL }{ }^{+} \mathrm{mTECS} \text {, significantly }}$ reduced by $\mathrm{m}(10 \mu \mathrm{M})$ with no effect by $\mathrm{ZVAD}$.fmk $(\mathrm{m}+\mathrm{z})$ but a marked reduction by nec-1 $(\mathrm{m}+\mathrm{n})$ comparable with cultures pretreated with a combination of $\mathrm{zVAD} . \mathrm{fmk}$ and nec-1 $(\mathrm{m}$ $+n+z)$. (e) The percentage of ${ }^{\text {TUNEL+ }}{ }^{m T E C s}$ and ( $f$ and $\mathbf{g}$ ) the mean fluorescence intensity (MFI) for pDrp $1^{\text {Ser616 }}$ and pDrp $1^{\text {Ser637 }}$ in similar cultures. ${ }^{* * *} P<0.0001$ versus $U T$ T (e), ${ }^{* *} P<0.01$ versus UT (f), ${ }^{*} P<0.05$ versus R1TNF, ${ }^{ \pm} P<0.05$ versus $\mathrm{R} 1 \mathrm{TNF}+\mathrm{m} .(\mathrm{g}){ }^{*} P<0.05$ versus $\mathrm{UT},{ }^{ \pm} P<0.5$ versus $\mathrm{R} 1 \mathrm{TNF}$, ${ }^{*} P<0.05$ versus $\mathrm{R} 1 \mathrm{TNF}+\mathrm{m}$; ns, not significant. Bars $=$ mean \pm S.E.M.; $n=3$ independent experiments from six separate organ culture experiments with similar results. (h) Schematic diagram of the consequences of R1TNF-mediated necroptosis in mTEC in RCC; ligation of TNFR1 results in the recruitment of RIPK1, facilitating its interaction with RIPK3, which in turn recruits and phosphorylates MLKL at Ser358 and Drp1 at Ser616 thus causing their co-localization with the mitochondria. A separate process causes a reduction in pDrp1 at ser637. Nec-1 inhibits RIPK1, and NSA inhibits MLKL and mdivi-1 inhibits Drp1 inhibiting cell death

of RIPK3. ${ }^{7}$ However, a recent report has suggested that RIPK3 oligomerization is sufficient to induce necroptosis, independent of the RHIM domain. ${ }^{57}$ Nevertheless, RIPK3 is now known to be the molecular switch for necroptosis, ${ }^{58-61}$ and its expression renders cells permissive to necroptosis upon TNF treatment ${ }^{7,10}$ via MLKL ${ }^{31,62}$ and Drp1 recruitment and phosphorylation. Using the PLA assay, ${ }^{63}$ we show that stimulation of RCC organ cultures with wtTNF or R1TNF 
induced RIPK1-RIPK3 interaction in MTECs, consistent with previous reports. ${ }^{6,7,10}$ Furthermore, we found that R1TNF induced an association between RIPK3 and pMLKL ${ }^{\text {Ser358 }}$ and that R1TNF increased pMLKL ${ }^{\text {Ser358 }}$ and $\mathrm{pDrp}^{\text {Ser616 }}$ and reduced Drp1 ${ }^{\text {ser637 }}$ in $\mathrm{mTECs.}$

The increase in pMLK ${ }^{\text {Ser358 }}$ and pDrp1 $1^{\text {Ser616 }}$ in TECs was associated with ${ }^{\mathrm{TUNEL}+}{ }^{\mathrm{mTEC}}$, further supporting a role for these phosphorylated proteins in necroptosis. Interestingly, immunogold electron microscopy analysis of R1TNF-treated cultures of RCC demonstrated the presence of $\mathrm{PMLKL}^{\mathrm{Ser} 358}$ in some mitochondria and on the plasma membrane of mTECs. This result is consistent with that of Cai et al., ${ }^{64}$ who reported translocation of RIPK3-dependent phosphorylated MLKL homotrimers to the cell plasma membrane, a process which leads to cell rupture. This finding is also supportive of a recent report by Rodriguez et al. ${ }^{20}$ Our immunofluorescence studies of wtTNF and R1TNF-treated cultures of RCC also demonstrated induction of pDrp1 $1^{\text {Ser616 }}$ and its co-localization with

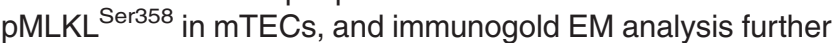
confirmed association of pMLKL ${ }^{\text {Ser358 }}$ and pDRP1 $1^{\text {Ser616 }}$ in the mitochondria of mTECs, implying that mitochondria may be a point of aggregation for execution of necrosis by these deathinducing components. ${ }^{65}$

Drp1 is regulated by posttranslational modifications such as phosphorylation. ${ }^{66,67}$ Drp1 phosphorylation at Ser616 has been linked to cancer invasion and growth and its increased expression has been reported in human lung cancer. ${ }^{68,69}$ In our hands, increased pDrp $1^{\text {Ser616 }}$ was associated with cell death; perhaps, its effects are context-dependent, so it couples to necroptosis when associated and co-localized with pMLKL ${ }^{\text {Ser358 }}$ but not in other environments. Differing extents of Drp1 and mitochondrial involvement in regulation of necroptosis have been reported, which most likely depend on the model studied. In the human organ culture model used here, there is a heterogeneous cell population, so factors that exert a spectrum of bioactivities may influence cell death regulation differently to experiments in a pure cell line. Our observation of rescued cell death mediated by TNF using mdivi-1, a selective inhibitor of Drp1, its correlation with phosphorylation of Drp1 at Ser616 and its co-localization with mitochondria strongly implicate them as likely targets in TNF-mediated necroptosis in RCC, though we have not proven this conclusively. In contrast to pDrp1 $1^{\text {Ser616, }}$, wtTNF and R1TNF reduced pDrp1 ${ }^{\text {ser637 }}$ expression in mTECs. Loss of this site is linked to Drp1 activation, a process thought to be regulated by mitochondrial protein phosphatase PGAM5. ${ }^{15,23}$ However, the requirement for PGAM5 in necroptosis induction has been challenged by others. ${ }^{70}$ Interestingly, necroptosis pathway inhibitors did not reverse the reduction in pDrp $1^{\text {Ser637 }}$ induced by R1TNF, so its relationship to the necroptosis pathway is unclear. Further work will be required to elucidate its role in TNF signaling and whether PGAM5 is important for mediating TNF-induced necroptosis in RCC. Collectively, our data strongly suggest that TNF-induced necroptosis in mTECs in RCC occurs via altered phosphorylation of MLKL/Drp1 and that this process may involve mitochondrial localization and possibly the plasma membrane. However, further studies will be needed to clarify the causal connections. ${ }^{48}$

Finally, we analyzed how these components contribute to cell death using small molecule inhibitors. It is well established that secondary necrosis can occur downstream of apoptosis, which is different from necroptosis. ${ }^{29,30}$ To test whether this explains the necrosis in our cultures, we used zVAD.fmk, a pan-caspase inhibitor. ${ }^{10,32,50,58}$ We show that treatment with zVAD.fmk resulted in only a minor inhibition of TNFR1-mediated cell death in mTECs consistent with our previous report that R1TNF induces expression of cleaved active caspase $3^{\mathrm{p} 175}$ in some mTECs. ${ }^{34}$ However, Nec-1, an allosteric RIPK1 inhibitor was highly effective at preventing cell death consistent with previous reports, ${ }^{50,51}$ and the combined addition of ZVAD.fmk and Nec-1 appeared to have an additive effect. These data imply dominance of a caspase-independent mode of cell death in mTECs, consistent with other studies. ${ }^{71}$

To further characterize the specific roles of MLKL and Drp1 in TNF-induced necroptosis in organ cultures of RCC and NK, we utilized the inhibitors NSA (inhibitor of MLKL) and mdivi-1 (a selective inhibitor of Drp1). We found that NSA reduced the number of ${ }^{\text {TUNEL+}}{ }^{m T E C s}$ back to untreated levels, while mdivi-1 was less effective at the concentration used. NSA- and mdivi-1-mediated death inhibition was associated with a significant reduction in expression of the relevant phosphorylated proteins; $\mathrm{pMLKL}{ }^{\text {Ser358 }}$ by NSA and $\mathrm{pDrp} 1^{\text {Ser616 }}$ by mdivi-1. NSA also attenuated phosphorylation of Drp1 ${ }^{\text {Ser616 }}$ (data not shown), consistent with a previous report. ${ }^{23}$ mdivi-1 is a quinazolinone derivative, attenuating Drp1 self-assembly, thereby causing the inhibition of mitochondrial fission. Owing to its potential in preventing mitochondrial fragmentation, mdivi-1 has shown protective efficacy in a number of disease models, including acute kidney injury, heart ischemia/reperfusion injury and Parkinson's disease. ${ }^{72}$ Our findings are consistent with earlier reports that demonstrate a protective effect of mdivi-1 by attenuating R1TNF-induced necroptotic death. ${ }^{72,73}$ The pathway we uncovered of R1TNF-mediated necroptosis in mTECs in RCC is schematized in Figure 6h.

In summary, our data provide new evidence demonstrating that TNF is an inducer of necroptosis in mTECs in organ culture via TNFR1, that necroptosis is the predominant form of cell death and that TNF-regulated necrosis occurs through a RIPK1/RIPK3/MLKL/Drp1 axis. Given that our system is closer to the situation in vivo, our findings support the development of a therapeutic strategy targeting nonapoptotic cell death pathways in RCC especially if they are resistant to pro-apoptotic treatment.

\section{Materials and Methods}

Reagents/antibodies. The antibodies used were as follows: anti-RIPK1 (cat NBP1-77077) (Novus Biologicals, Oxford, UK), anti-RIPK1 (cat 3493S) (New England Biolabs, Hitchin, UK), anti-RIPK1 (cat ab56815), anti-RIPK3 (cat ab16090), anti-RIPK3 (cat ab56164) (Abcam, Cambridge, UK). Anti-RIPK3 (cat GTX107574, GenTex, Irvine, CA, USA), anti-RIPK3 (cs-13526S), anti-MLKL and anti-phosphorylated MLKL ${ }^{\text {Ser358 }}$ (phospho-Ser358) (cat 17-10400) and antimitochondria (MAB1273, Millipore, Watford, UK); anti-phosphorylated MLKL ${ }^{\text {Ser358 }}$ (cat ab187091), anti-c-FLIP (cat ab6144) and anti-Caspase- $8^{\text {p18 }}$ (cat ab25901) are from Abcam, anti-NF $\kappa_{K} B$ 65 $5^{\text {p-ser276 }}$ (cat 3037S), anti-pDrp1 ${ }^{\text {Ser616 }}$ (cat cs-3455S), anti-pDrp1 ${ }^{\text {Ser637 }}$ (cat cs-4867S) are from New England Biolabs. Rabbit anti-cytokeratin (CK) (cat sc15367) is from Insight Biotechnology Ltd, Wembley, UK, and mouse anti-CK (cat VP-C420) is from Vector Laboratories, Peterborough, UK. Blocking peptides for RIPK1 (cat $\sim$ NBP1-77077PEP) are from Novus

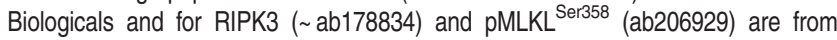
Abcam. zVAD.fmk (pan-caspase inhibitor N-benzyloxycarbonyl-Val-Ala-Asp-fluoromethylketone; cat $\sim$ G7231) is from Promega, Madison, WI, USA; PDTC, 3,3'-diaminobenzidine substrate (DAB), Necrostatin-1 (Nec-1, cat N9037) and 
mdivi-1 (3-(2, 4-dichloro-5-methoxyphenyl)-2-sulfanyl-4(3H)-quinazolinone) are from Sigma-Aldrich (Gillingham, UK). TUNEL-In Situ Cell Death Detection Kit (cat 11767291910) is from Roche Diagnostics, West Sussex, UK. Five nanometer and $15 \mathrm{~nm}$-conjugated gold particles are from British Biocell (Cardiff, UK); Hoechst 33342 is from Thermo Fisher Scientific (Paisley, UK); wild-type TNF (wtTNF) (cat 210-TA-020; R\&D systems, Oxford, UK) and TNFR-specific muteins (R1TNF and R2TNF) were a generous gift from Professor Peter Vandenabeele (Gwent, Belgium).

RCC and NK organ cultures. All experiments using human tissue were performed with the written informed consent of patients and the approval of the local Ethical Committee and Addenbrooke's Hospital Tissue Bank. RCC tissue grade 1 and adjacent non-tumor kidney tissue (NK) $(n=6)$ from radical nephrectomies were randomly dissected and processed for organ culture as previously reported. ${ }^{74}$ Briefly, duplicate $<1 \mathrm{~mm}^{3}$ fragments were placed in M199 medium in 96-well plates and either left in medium alone (untreated; UT) or pretreated with wtTNF $(10 \mathrm{ng} / \mathrm{ml}$ ) or R1TNF or R2TNF $(1 \mu \mathrm{g} / \mathrm{ml})$ for $3 \mathrm{~h}$ at $37^{\circ} \mathrm{C}$. Parallel cultures were pretreated with zVAD.fmk $(20 \mu \mathrm{M})^{50,51,58,75}$ or Nec-1 $(30 \mu \mathrm{M})^{51,76,77}$ or with a mixture of ZVAD. fmk and Nec-1 for $1 \mathrm{~h}$ prior to wtTNF or R1TNF or R2TNF. In addition, some cultures were pretreated for $1 \mathrm{~h}$ with different dose of necrosulfoximide (NSA; inhibitor of pMLKL) $(5,10,20,50 \mu \mathrm{M})$ or mdivi-1 $(10 \mu \mathrm{M}$; mitochondrial division inhibitor-1 targets pDrp1) before TNF or R1TNF or R2TNF with Nec-1 and/or zVAD.fmk. Additional, duplicate samples were either treated with $50 \mu \mathrm{g} / \mathrm{ml}$ (or $300 \mu \mathrm{M}$ ) PDTC $^{34}$ or left untreated for 30 min before TNF treatment. All cultures were fixed in $4 \%$ paraformaldehyde and wax sections stained with hematoxylin and eosin for morphological studies, immunofluorescence, immunohistochemistry, TUNEL and in situ hybridization. Images of hematoxylin and eosin sections were captured using a Leitz Laborlux 12 Microscope with Infinity 2 camera (Lumenera Corporation, Ontario, Canada).

Immunohistochemical and immunofluorescence analyses (IHC and IF). RCC, NK and corresponding organ cultures were subjected to IHC and IF as previously described. ${ }^{74}$ Briefly, some sections were incubated with anti-RIPK1, -RIPK3, -pMLKL ${ }^{\text {Ser358, }}$-pDrp1 ${ }^{\text {Ser616 }}, \mathrm{pDrp1}^{\text {Ser637 }}$ and pan-cytokeratin and some sections immunostained for pMLKL ${ }^{\text {Ser358 }}$ and -pDrp1 ${ }^{\text {Ser616 }}$ or pDrp1 ${ }^{\text {Ser637 }}$ using Zenon Fab reagents, ${ }^{7}$ followed by incubation with flourochrome-conjugated secondary antibody (Northern Light ${ }^{498}$ or ${ }^{557}$ ) (R\&D Systems) plus Hoechst 333342. For $\mathrm{IHC}$, sections were pretreated with $30 \% \mathrm{H}_{2} \mathrm{O}_{2}$ before incubation with primary antibodies, followed by a peroxidase-conjugated secondary antibody and DAB as chromogen and counterstained with hematoxylin. Parallel cultures treated with or without PDTC were also examined for expression of $\mathrm{NF}_{\kappa} \mathrm{Bp} 65^{\mathrm{p}-\mathrm{ser} 276}, \mathrm{c}$-FLIP and active Caspase $8^{\text {p18. }}$. Negative controls included pre-adsorption of primary antibodies with blocking peptides overnight at $4{ }^{\circ} \mathrm{C}$ prior to immunostaining and also replacement of the primary antibody with an isotype-specific sera. To further confirm specificity of the antibodies to RIPK1, RIPK3, MLKL and DRP1 used in this study, we carried out gene knockdown experiments on human HEK293 cells using siRNA against each target protein (as these cells show high transfection efficiency). For this, cells were reverse-transfected with $100 \mathrm{nM}$ of the appropriate siRNA (GE Healthcare UK Ltd, Buckinghampshire, UK) in 8-well slide chambers using the TurboFect transfection reagent (Thermo Fisher Scientific), according to the manufacturer's protocol. After $48 \mathrm{~h}$ of transfection, the cells were treated with ZVAD. fmk $(25 \mu \mathrm{M})$ and the Smac-mimetic LCL-61 $(100 \mu \mathrm{M})$ (Selleckchem, Houston, TX USA) for 30 min prior to treatment with TNF (10 ng/ml) for $4 \mathrm{~h}$ and then subjected to IF. siRNAs used include Accell Human Control siRNA non-targeting pool Cat $\sim$ D-001910-10-20; Accell Human RIPK1 siRNA SMARTpool Cat E-00444500-000, Accell Human RIPK3 siRNA SMARTpool Cat E-003534-00-0005, Accell Human MLKL siRNA SMARTpool Cat E-005326-00-0005, Accell Human DRP1 siRNA SMRTpool Cat $\sim$ E-012092-00-0005 (GE Healthcare Ltd).

Photomicrographs were captured using a on a SPE-confocal laser scanning microscopy (Leica Microsystems Ltd, Milton Keynes, UK) and IF images were captured on a confocal laser scanning microscopy. The mean fluorescence intensity was quantified in Image J. All data were transferred to GraphPad Prism 5.0 for statistical analysis.

In situ PLA. The principle of the in situ PLA was reported previously. ${ }^{63}$ Briefly, when two proteins are closer than $40 \mathrm{~nm}$, signals can be detected. In situ PLA assay was performed using the Duolink In Situ Detection Regents Red (Cat DU092008; Sigma-Aldrich) according to the manufacturer's instructions. For details, refer to Supplementary Methods. The number of in situ fluorescent PLA signals (red spots) was counted in mTECs in 10 random fields of view at $\times 40$ magnification. The number of signals per cell in the negative controls incubated with only one of the primary antibodies (RIPK1 and RIPK3) was also counted and the increase in signal calculated as the ratio of the number of signals per cell in the sample divided by the sum of the signals in the negative controls, as previously reported..$^{79}$ Images were acquired on a confocal laser scanning microscopy and prepared using Photoshop CS6 software.

In situ hybridization (ISH). As previously described, ${ }^{74}$ paraffin sections of RCC and NK organ cultures were hybridized overnight at $37^{\circ} \mathrm{C}$ with single-stranded anti-sense DNA oligonucleotide probes $5^{\prime}$-end labeled with digoxigenin specific for human RIPK1 (NM_003804) or human RIPK3 (NM_006871) (Eurofins Genomics, Ebersberg, Germany) followed by anti-digoxigenin-11-dUTP-conjugated-alkaline phosphatase (AP) (Roche). Gene expression was visualized as described in Supplementary Methods.

Terminal deoxynucleotidyl transferase (TdT)-mediated-digoxigenin-11-dUTP nick end labeling (TUNEL). TUNEL was used to detect DNA fragmentation in RCC and NK organ cultures treated with wtTNF, R1TNF and R2TNF as previously described. ${ }^{74}$ The number of TUNEL ${ }^{+}$dead TECs per total number of viable cells were counted in 10 high power fields of view at $\times 40$ magnification and scored by two observers blinded to the treatments and the data presented as percentage of dead TECs. For details of TUNEL assay, see Supplementary Methods.

Immunoblotting. RCC and NK tissue were processed for immunoblotting as previously described. ${ }^{27}$ Following lysis, $50 \mu \mathrm{g}$ of each sample was separated by SDS-PAGE, and transferred to a nitrocellulose membrane then probed for RIPK1 and RIPK3 (1:1000) and signals detected by enhanced chemiluminescence according to the manufacturer's instructions. Relative protein levels were normalized to $\beta$-actin and, calculated using Image $\mathrm{J}$ and Microsoft Excel.

Ultrastructure and immunogold electron microscopy. As previously described, ${ }^{80}$ after fixation in glutaraldehyde/paraformaldehyde $(2.5 \% / 1 \%)$, RCC and NK organ cultures were subjected to $1 \%$ osmium ferrocyanide for $1 \mathrm{~h}$, dehydrated in an ascending series of ethanol solutions, and embedded in Spurr's resin. Fifty nanometer sections were stained with uranyl acetate and lead citrate. For immunogold staining, as previously described, sections were stained for pMLKL ${ }^{\text {Ser358 }}$ or pDrp1 $1^{\text {Ser616 }}$ and mitochondria (1:5) overnight and further incubated with 5 and $15 \mathrm{~nm}$ gold particles (British Biocell) (1:100), stained with uranyl acetate and lead citrate before viewing in a Hitachi Capital (UK) PLC, Leeds West Yorkshire at an accelerating voltage of $80 \mathrm{kV}$.

Statistical analyses. All data represent mean \pm S.E.M. of $n=3$ independent experiments from at least six different patient organ cultures unless otherwise stated. Differences between two groups were analyzed by Student's $t$-test, and between $>2$ groups by one-way ANOVA followed by Bonferroni's post hoc $t$-test in GraphPad Prism version 5.02 (La Jolla, CA, USA). $P<0.05$ was regarded significant.

\section{Conflict of Interest}

The authors declare no conflict of interest.

Acknowledgements. We would like to thank the National Institute for Health Research (NIHR) Cambridge Biomedical Research Centre (WL, JRB and AYW), Kidney Research UK (RSA, JW and JRB) and NIH grant R01-HL36003 (JSP). We would like to express gratitude to The Human Research Tissue Bank who is supported by the NIHR Cambridge Biomedical Research Centre at the Cambridge University Hospitals NHS Foundation Trust for help with accessing the tissue used in this study.

1. Flanigan RC, Salmon SE, Blumenstein BA, Bearman SI, Roy V, McGrath PC et al. Nephrectomy followed by interferon alfa-2b compared with interferon alfa- $2 \mathrm{~b}$ alone for metastatic renal-cell cancer. N Engl J Med 2001; 345: 1655-1659.

2. Vandenabeele $P$, Declercq W, Van Herreweghe F, Vanden Berghe T. The role of the kinases RIP1 and RIP3 in TNF-induced necrosis. Sci Signal 2010; 3: re4. 
3. Hu X, Han W, Li L. Targeting the weak point of cancer by induction of necroptosis. Autophagy 2007; 3: 490-492

4. Linkermann A, Green DR. Necroptosis. N Engl J Med 2014; 370: 455-465.

5. Al-Lamki RS, Bradley JR, Pober JS. Human organ culture as a tool for analyzing the response to tumor necrosis factor. Curr Trends Immunol 2011; 12: 49-66.

6. Cho YS, Challa S, Moquin D, Genga R, Ray TD, Guildford M et al. Phosphorylation-driven assembly of the RIP1-RIP3 complex regulates programmed necrosis and virus-induced inflammation. Cell 2009; 137: 1112-1123.

7. He S, Wang L, Miao L, Wang T, Du F, Zhao L et al. Receptor interacting protein kinase-3 determines cellular necrotic response to TNF-alpha. Cell 2009; 137: 1100-1111.

8. Linkermann A, Brasen JH, Himmerkus N, Liu S, Huber TB, Kunzendorf U et al. Rip1 (receptor-interacting protein kinase 1) mediates necroptosis and contributes to renal ischemia/reperfusion injury. Kidney Int 2012; 81: 751-761.

9. Linkermann A, Hackl MJ, Kunzendorf U, Walczak H, Krautwald S, Jevnikar AM. Necroptosis in immunity and ischemia-reperfusion injury. Am J Transplant 2013; 13: 2797-2804.

10. Zhang DW, Shao J, Lin J, Zhang N, Lu BJ, Lin SC et al. RIP3, an energy metabolism regulator that switches TNF-induced cell death from apoptosis to necrosis. Science 2009; 325: 332-336

11. Chan FK, Shisler J, Bixby JG, Felices M, Zheng L, Appel M et al. A role for tumor necrosis factor receptor-2 and receptor-interacting protein in programmed necrosis and antiviral responses. J Biol Chem 2003; 278: 51613-51621.

12. Dillon CP, Weinlich R, Rodriguez DA, Cripps JG, Quarato G, Gurung P et al. RIPK1 blocks early postnatal lethality mediated by caspase-8 and RIPK3. Cell 2014; 157: 1189-1202.

13. Lu JV, Chen HC, Walsh CM. Necroptotic signaling in adaptive and innate immunity. Semin Cell Dev Biol 2014; 35: 33-39.

14. Stanger BZ, Leder P, Lee TH, Kim E, Seed B. RIP: a novel protein containing a death domain that interacts with Fas/APO-1 (CD95) in yeast and causes cell death. Cell 1995; 81: 513-523.

15. Sun L, Wang H, Wang Z, He S, Chen S, Liao D et al. Mixed lineage kinase domain-like protein mediates necrosis signaling downstream of RIP3 kinase. Cell 2012; 148: 213-227.

16. Bertrand MJ, Vandenabeele P. The ripoptosome: death decision in the cytosol. Mol Cell 2011; 43: 323-325.

17. Zhao J, Jitkaew S, Cai Z, Choksi S, Li Q, Luo J et al. Mixed lineage kinase domain-like is a key receptor interacting protein 3 downstream component of TNF-induced necrosis. Proc Natl Acad Sci USA 2012; 109: 5322-5327.

18. Wang H, Sun L, Su L, Rizo J, Liu L, Wang LF et al. Mixed lineage kinase domain-like protein MLKL causes necrotic membrane disruption upon phosphorylation by RIP3. Mol Cell 2014; 54: 133-146.

19. Moujalled DM, Cook WD, Murphy JM, Vaux DL. Necroptosis induced by RIPK3 requires MLKL but not Drp1. Cell Death Dis 2014; 5: e1086.

20. Rodriguez DA, Weinlich R, Brown S, Guy C, Fitzgerald P, Dillon CP et al. Characterization of RIPK3-mediated phosphorylation of the activation loop of MLKL during necroptosis. Cell Death Differ 2015; 23: 76-88.

21. Chang CR, Blackstone C. Drp1 phosphorylation and mitochondrial regulation. EMBO Rep 2007; 8: 1088-1089 author reply 1089-1090.

22. Cribbs JT, Strack S. Reversible phosphorylation of Drp1 by cyclic AMP-dependent protein kinase and calcineurin regulates mitochondrial fission and cell death. EMBO Rep 2007; 8 : 939-944.

23. Wang $\mathrm{Z}$, Jiang $\mathrm{H}$, Chen $\mathrm{S}$, Du F, Wang $X$. The mitochondrial phosphatase PGAM5 functions at the convergence point of multiple necrotic death pathways. Cell 2012; 148: 228-243.

24. Breckenridge DG, Kang BH, Kokel D, Mitani S, Staehelin LA, Xue D. Caenorhabditis elegans drp-1 and fis-2 regulate distinct cell-death execution pathways downstream of ced-3 and independent of ced-9. Mol Cell 2008; 31: 586-597.

25. Frank S, Gaume B, Bergmann-Leitner ES, Leitner WW, Robert EG, Catez F et al. The role of dynamin-related protein 1, a mediator of mitochondrial fission, in apoptosis. Dev Cell 2001; 1 : 515-525.

26. Kashatus JA, Nascimento A, Myers LJ, Sher A, Byrne FL, Hoehn KL et al. Erk2 phosphorylation of Drp1 promotes mitochondrial fission and MAPK-driven tumor growth. Mol Cell 2015; 57: 537-551

27. Al-Lamki RS, Sadler TJ, Wang J, Reid MJ, Warren AY, Movassagh M et al. Tumor necrosis factor receptor expression and signaling in renal cell carcinoma. Am J Pathol 2010; 177: 943-954.

28. Vandenabeele P, Galluzzi L, Vanden Berghe T, Kroemer G. Molecular mechanisms of necroptosis: an ordered cellular explosion. Nat Rev Mol Cell Biol 2010; 11: 700-714.

29. Balmer J, Zulliger R, Roberti S, Enzmann V. Retinal cell death caused by sodium iodate involves multiple caspase-dependent and caspase-independent cell-death pathways. Int $\mathrm{J}$ Mol Sci 2015; 16: 15086-15103.

30. Sawai H, Domae N. Discrimination between primary necrosis and apoptosis by necrostatin-1 in Annexin V-positive/propidium iodide-negative cells. Biochem Biophys Res Commun 2011; 411: 569-573

31. Dondelinger Y, Aguileta MA, Goossens V, Dubuisson C, Grootjans S, Dejardin E et al. RIPK3 contributes to TNFR1-mediated RIPK1 kinase-dependent apoptosis in conditions of cIAP1/2 depletion or TAK1 kinase inhibition. Cell Death Differ 2013; 20: 1381-1392.

32. Festjens N, Vanden Berghe T, Cornelis S, Vandenabeele P. RIP1, a kinase on the crossroads of a cell's decision to live or die. Cell Death Differ 2007; 14: 400-410.

33. Newton K. RIPK1 and RIPK3: critical regulators of inflammation and cell death. Trends Cell Biol 2015; 25: 347-353.
34. Al-Lamki RS, Wang J, Tolkovsky AM, Bradley JA, Griffin JL, Thiru S et al. TL1A both promotes and protects from renal inflammation and injury. J Am Soc Nephrol 2008; 19: 953-960.

35. Lee SH, Kim HS, Kim SY, Lee YS, Park WS, Kim SH et al. Increased expression of FLIP, an inhibitor of Fas-mediated apoptosis, in stomach cancer. APMIS 2003; 111: 309-314.

36. Shirley S, Micheau O. Targeting c-FLIP in cancer. Cancer Lett 2013; 332: 141-150.

37. Ye YC, Wang HJ, Chen L, Liu WW, Tashiro S, Onodera S et al. Negatively-regulated necroptosis by autophagy required caspase- 6 activation in TNFalpha-treated murine fibrosarcoma L929 cells. Int Immunopharmacol 2013; 17: 548-555.

38. Cassidy-Stone A, Chipuk JE, Ingerman E, Song C, Yoo C, Kuwana T et al. Chemical inhibition of the mitochondrial division dynamin reveals its role in Bax/Bak-dependent mitochondrial outer membrane permeabilization. Dev Cell 2008; 14: 193-204.

39. Ong SB, Kalkhoran SB, Cabrera-Fuentes HA, Hausenloy DJ. Mitochondrial fusion and fission proteins as novel therapeutic targets for treating cardiovascular disease. Eur $J$ Pharmacol 2015; 763(Pt A): 104-114.

40. Tanaka A, Youle RJ. A chemical inhibitor of DRP1 uncouples mitochondrial fission and apoptosis. Mol Cell 2008; 29: 409-410.

41. Carswell EA, Old LJ, Kassel RL, Green S, Fiore N, Williamson B. An endotoxin-induced serum factor that causes necrosis of tumors. Proc Natl Acad Sci USA 1975; 72: 3666-3670.

42. Oettgen HF, Carswell EA, Kassel RL, Fiore N, Williamson B, Hoffmann MK et al. Endotoxininduced tumor necrosis factor. Recent Results Cancer Res 1980; 75: 207-212.

43. Norman KE, Williams TJ, Feldmann M, Rossi AG. Effect of soluble P55 tumour-necrosis factor binding fusion protein on the local Shwartzman and Arthus reactions. Br J Pharmaco 1996; 117: 471-478.

44. Bharadwaj U, Marin-Muller C, Li M, Chen C, Yao Q. Mesothelin confers pancreatic cancer cell resistance to TNF-alpha-induced apoptosis through Akt/PI3K/NF-kappaB activation and IL-6/Mcl-1 overexpression. Mol Cancer 2011; 10: 106

45. Han J, Soletti RC, Sadarangani A, Sridevi P, Ramirez ME, Eckmann L et al. Nuclear expression of beta-catenin promotes RB stability and resistance to TNF-induced apoptosis in colon cancer cells. Mol Cancer Res 2013; 11: 207-218.

46. Vanlangenakker $N$, Bertrand $M J$, Bogaert $P$, Vandenabeele $P$, Vanden Berghe $T$. TNF-induced necroptosis in L929 cells is tightly regulated by multiple TNFR1 complex I and II members. Cell Death Dis 2011; 2: e230.

47. Linkermann A, Brasen JH, De Zen F, Weinlich R, Schwendener RA, Green DR et al. Dichotomy between RIP1- and RIP3-mediated necroptosis in tumor necrosis factor-alphainduced shock. Mol Med 2012; 18: 577-586.

48. Remijsen Q, Goossens V, Grootjans S, Van den Haute C, Vanlangenakker N, Dondelinger Y et al. Depletion of RIPK3 or MLKL blocks TNF-driven necroptosis and switches towards a delayed RIPK1 kinase-dependent apoptosis. Cell Death Dis 2014; 5: e1004.

49. Declercq W, Vanden Berghe T, Vandenabeele P. RIP kinases at the crossroads of cell death and survival. Cell 2009; 138: 229-232.

50. Degterev A, Hitomi J, Germscheid M, Ch'en IL, Korkina O, Teng X et al. Identification of RIP1 kinase as a specific cellular target of necrostatins. Nat Chem Biol 2008; 4: 313-321.

51. Degterev A, Huang Z, Boyce M, Li Y, Jagtap P, Mizushima N et al. Chemical inhibitor of nonapoptotic cell death with therapeutic potential for ischemic brain injury. Nat Chem Biol 2005; 1: 112-119.

52. Moriwaki K, Chan FK. RIP3: a molecular switch for necrosis and inflammation. Genes Dev 2013; 27: 1640-1649.

53. Vanlangenakker $\mathrm{N}$, Vanden Berghe $\mathrm{T}$, Vandenabeele $\mathrm{P}$. Many stimuli pull the necrotic trigger an overview. Cell Death Differ 2012; 19: 75-86.

54. Park S, Zhao D, Hatanpaa KJ, Mickey BE, Saha D, Boothman DA et al. RIP1 activates PI3K-Akt via a dual mechanism involving NF-kappaB-mediated inhibition of the mTOR-S6KIRS1 negative feedback loop and down-regulation of PTEN. Cancer Res 2009; 69 : 4107-4111

55. Wang Q, Chen W, Xu X, Li B, He W, Padilla MT et al. RIP1 potentiates BPDE-induced transformation in human bronchial epithelial cells through catalase-mediated suppression of excessive reactive oxygen species. Carcinogenesis 2013; 34: 2119-2128.

56. O'Donnell MA, Legarda-Addison D, Skountzos P, Yeh WC, Ting AT. Ubiquitination of RIP1 regulates an NF-kappaB-independent cell-death switch in TNF signaling. Curr Biol 2007; 17: 418-424

57. Orozco S, Yatim N, Werner MR, Tran H, Gunja SY, Tait SW et al. RIPK1 both positively and negatively regulates RIPK3 oligomerization and necroptosis. Cell Death Differ 2014; 21: 1511-1521.

58. Hitomi J, Christofferson DE, Ng A, Yao J, Degterev A, Xavier RJ et al. Identification of a molecular signaling network that regulates a cellular necrotic cell death pathway. Cell 2008; 135: 1311-1323.

59. Linkermann A, De Zen F, Weinberg J, Kunzendorf U, Krautwald S. Programmed necrosis in acute kidney injury. Nephrol Dial Transplant 2012; 27: 3412-3419.

60. Linkermann A, Skouta R, Himmerkus N, Mulay SR, Dewitz C, De Zen F et al. Synchronized renal tubular cell death involves ferroptosis. Proc Natl Acad Sci USA 2014; 111: 16836-16841.

61. Newton K, Dugger DL, Wickliffe KE, Kapoor N, de Almagro MC, Vucic D et al. Activity of protein kinase RIPK3 determines whether cells die by necroptosis or apoptosis. Science 2014; 343: 1357-1360.

62. Wu J, Huang Z, Ren J, Zhang Z, He P, Li Y et al. Mlkl knockout mice demonstrate the indispensable role of Mlkl in necroptosis. Cell Res 2013; 23: 994-1006.

63. Soderberg $\mathrm{O}$, Gullberg M, Jarvius M, Ridderstrale K, Leuchowius KJ, Jarvius J et al. Direct observation of individual endogenous protein complexes in situ by proximity ligation Nat Methods 2006; 3: 995-1000. 
64. Cai Z, Jitkaew S, Zhao J, Chiang HC, Choksi S, Liu J et al. Plasma membrane translocation of trimerized MLKL protein is required for TNF-induced necroptosis. Nat Cell Biol 2014; 16: $55-65$.

65. Pradeep H, Sharma B, Rajanikant GK. Drp1 in ischemic neuronal death: an unusual suspect. Curr Med Chem 2014; 21: 2183-2189.

66. Chang $\mathrm{CR}$, Blackstone $\mathrm{C}$. Dynamic regulation of mitochondrial fission through modification of the dynamin-related protein Drp1. Ann N Y Acad Sci 2010; 1201: 34-39.

67. Santel A, Frank S. Shaping mitochondria: The complex posttranslational regulation of the mitochondrial fission protein DRP1. IUBMB Life 2008; 60: 448-455.

68. Chiang YY, Chen SL, Hsiao YT, Huang CH, Lin TY, Chiang IP et al. Nuclear expression of dynamin-related protein 1 in lung adenocarcinomas. Mod Pathol 2009; 22: 1139-1150.

69. Rehman J, Zhang HJ, Toth PT, Zhang Y, Marsboom G, Hong Z et al. Inhibition of mitochondrial fission prevents cell cycle progression in lung cancer. FASEB J 2012; 26: 2175-2186.

70. Murphy JM, Czabotar PE, Hildebrand JM, Lucet IS, Zhang JG, Alvarez-Diaz S et al. The pseudokinase MLKL mediates necroptosis via a molecular switch mechanism. Immunity 2013; 39: 443-453.

71. Kolenko V, Uzzo RG, Bukowski R, Bander NH, Novick AC, Hsi ED et al. Dead or dying: necrosis versus apoptosis in caspase-deficient human renal cell carcinoma. Cancer Res 1999; 59: 2838-2842.

72. Lackner LL, Nunnari J. Small molecule inhibitors of mitochondrial division: tools that translate basic biological research into medicine. Chem Biol 2010; 17: 578-583.

73. Zhang N, Wang S, Li Y, Che L, Zhao Q. A selective inhibitor of Drp1, mdivi-1, acts against cerebral ischemia/reperfusion injury via an anti-apoptotic pathway in rats. Neurosci Lett 2013; 535: 104-109.

74. Al-Lamki RS, Wang J, Vandenabeele P, Bradley JA, Thiru S, Luo D et al. TNFR1- and TNFR2-mediated signaling pathways in human kidney are cell type-specific and differentially contribute to renal injury. FASEB J 2005; 19: 1637-1645.

75. Lin Y, Choksi S, Shen HM, Yang QF, Hur GM, Kim YS et al. Tumor necrosis factor-induced nonapoptotic cell death requires receptor-interacting protein-mediated cellular reactive oxygen species accumulation. J Biol Chem 2004; 279: 10822-10828.
76. Devalaraja-Narashimha K, Diener AM, Padanilam BJ. Cyclophilin D gene ablation protects mice from ischemic renal injury. Am J Physiol Renal Physiol 2009; 297 : F749-F759.

77. Osborn SL, Diehl G, Han SJ, Xue L, Kurd N, Hsieh K et al. Fas-associated death domain (FADD) is a negative regulator of T-cell receptor-mediated necroptosis. Proc Natl Acad Sci USA 2010; 107: 13034-13039.

78. Al-Lamki RS, Lu W, Wang J, Yang J, Sargeant TJ, Wells R et al. TNF, acting through inducibly expressed TNFR2, drives activation and cell cycle entry of c-Kit+ cardiac stem cells in ischemic heart disease. Stem Cells 2013; 31: 1881-1892.

79. Schedin-Weiss S, Inoue M, Teranishi Y, Yamamoto NG, Karlstrom H, Winblad B et al. Visualizing active enzyme complexes using a photoreactive inhibitor for proximity ligationapplication on gamma-secretase. PLoS One 2013; 8: e63962.

80. Al-Lamki RS, Wang J, Skepper JN, Thiru S, Pober JS, Bradley JR. Expression of tumor necrosis factor receptors in normal kidney and rejecting renal transplants. Lab Invest 2001; 81: $1503-1515$

(c) (i) Cell Death and Disease is an open-access journal published by Nature Publishing Group. This work is licensed under a Creative Commons Attribution 4.0 International License. The images or other third party material in this article are included in the article's Creative Commons license, unless indicated otherwise in the credit line; if the material is not included under the Creative Commons license, users will need to obtain permission from the license holder to reproduce the material. To view a copy of this license, visit http://creativecommons.org/licenses/by/4.0/

(C) The Author(s) 2016

Supplementary Information accompanies this paper on Cell Death and Disease website (http://www.nature.com/cddis) 